\title{
Brain State Effects on Layer 4 of the Awake Visual Cortex
}

\author{
Jun Zhuang (庄骏), ${ }^{1}$ Yulia Bereshpolova, ${ }^{1}$ Carl R. Stoelzel, ${ }^{1}$ Joseph M. Huff, ${ }^{1}$ Xiaojuan Hei (黑晓娟), ${ }^{1}$ \\ Jose-Manuel Alonso, ${ }^{1,2}$ and Harvey A. Swadlow ${ }^{1,2}$ \\ ${ }^{1}$ Department of Psychology, University of Connecticut, Storrs, Connecticut 06269, and 2Department of Biological Sciences, State University of New York \\ College of Optometry, New York, New York 10036
}

Awake mammals can switch between alert and nonalert brain states hundreds of times per day. Here, we study the effects of alertness on two cell classes in layer 4 of primary visual cortex of awake rabbits: presumptive excitatory "simple" cells and presumptive fast-spike inhibitory neurons (suspected inhibitory interneurons). We show that in both cell classes, alertness increases the strength and greatly enhances the reliability of visual responses. In simple cells, alertness also increases the temporal frequency bandwidth, but preserves contrast sensitivity, orientation tuning, and selectivity for direction and spatial frequency. Finally, alertness selectively suppresses the simple cell responses to high-contrast stimuli and stimuli moving orthogonal to the preferred direction, effectively enhancing mid-contrast borders. Using a population coding model, we show that these effects of alertness in simple cells - enhanced reliability, higher gain, and increased suppression in orthogonal orientation- could play a major role at increasing the speed of cortical feature detection.

\section{Introduction}

The "waking state" is not unitary. It contains different brain states which can be distinguished by differences in behavior, physiological activity, or neurotransmitter release (Harris and Thiele, 2011; Lee and Dan, 2012), and these different awake brain states strongly affect information processing in sensory thalamus and cortices in cats (Wörgötter et al., 1998), mouse (Poulet and Petersen, 2008; Gentet et al., 2010; Niell and Stryker, 2010; Pinto et al., 2013; Polack et al., 2013), rats (Fanselow and Nicolelis, 1999; Castro-Alamancos, 2004; Goard and Dan, 2009; Otazu et al., 2009), and rabbits (Swadlow and Weyand, 1985, 1987; Swadlow, 1988; Bezdudnaya et al., 2006; Cano et al., 2006; Bereshpolova et al., 2011). Awake rabbits readily shift between alert and nonalert brain states, measured by the electroencephalogram (EEG). The transition between these states is often very rapid $(<1 s)$ and profoundly affects spiking statistics and receptive field (RF) properties in the lateral geniculate nucleus (LGN), where alertness significantly increases spontaneous firing rates, visual response gain, temporal frequency tuning peak/width, and the maintained response to stationary stimulation, but significantly decreases bursting rate (Swadlow and Weyand, 1985; Swadlow and Gusev, 2001; Bezdudnaya et al., 2006; Bereshpolova et al., 2011). By contrast, thalamocortical synaptic transmission is

Received Nov. 26, 2013; revised Jan. 8, 2014; accepted Feb. 5, 2014.

Author contributions: J.Z., Y.B., C.R.S., J.-M.A., and H.A.S. designed research; J.Z., Y.B., C.R.S., J.M.H., and X.H. performed research; J.Z., Y.B., C.R.S., J.M.H., X.H., J.M.A., and H.A.S. analyzed data; J.Z., Y.B., C.R.S., J.-M.A., and H.A.S. wrote the paper.

Supported by NIH Grant EY018251. We thank Victor Serdyukov for superb software development and hardware support.

The authors declare no competing financial interests.

Correspondence should be addressed to Harvey A. Swadlow, Department of Psychology, The University of Connecticut, 406 Babbidge Road, U-1020, Storrs, CT 06269. E-mail: harvey.swadlow@uconn.edu.

DOI:10.1523/JNEUROSCI.4969-13.2014

Copyright $\odot 2014$ the authors $\quad 0270-6474 / 14 / 343888-13 \$ 15.00 / 0$ remarkably stable across alert and nonalert states (Stoelzel et al., 2009), suggesting that layer 4 neurons, the major recipients of LGN input, may inherit the brain state effects from LGN. Surprisingly, unlike LGN cells, most suspected inhibitory interneurons (SINs) in layer 4 decrease their spontaneous firing rates during the alert state, whereas the spontaneous firing of layer 4 simple cells remains relatively constant (Bereshpolova et al., 2011), showing that brain state can have a different effect on visual cortex than thalamus. Notably, the two major cell classes in layer 4, putative excitatory simple cells and SINs, have markedly different response properties (Zhuang et al., 2013), suggesting very different roles in cortical computation. Here, we examine the visual response properties of identified layer 4 simple cells and SINs in primary visual cortex (V1) of fully awake rabbits during both alert and nonalert states. We found that the alertness increased the strength and reliability of visual responses in both cell classes while preserving their contrast sensitivity and spatial selectivity. Moreover, alertness selectively suppressed the visual responses of layer 4 simple cells to high contrast stimuli and stimuli moving orthogonal to the preferred direction. Finally, using a population coding model, we demonstrated that the enhanced reliability, enhanced response strength, and selective response suppression of layer 4 simple cells during alertness could significantly increase the speed of cortical computations that may underlie feature detection.

\section{Materials and Methods}

Recordings were obtained from monocular primary V1 of four awake adult female Dutch-Belted rabbits. All experiments were conducted with the approval of the University of Connecticut Animal Care and Use Committee in accordance with National Institutes of Health guidelines. All statistical comparisons reported were quantified as mean \pm SE with $p$ values obtained by two-tailed paired sample $t$ tests, if not specified. Error bars in each figure represent SEM. 


\section{Animal preparation and electrophysiological recording}

The general surgical procedures for chronic recordings have been described previously (Bezdudnaya et al., 2006; Stoelzel et al., 2008; Bereshpolova et al., 2011; Zhuang et al., 2013) and are reported only briefly here. Under ketamine-acepromazine anesthesia, eight stainless steel screws and a stainless steel rod, oriented in a rostrocaudal direction, were installed on the exposed surface of the skull by acrylic cement. The rod was then used to rigidly hold the rabbit's head during the electrode implantation and recording sessions. The space between the wound margin and the acrylic cement was filled with silicone rubber. Recordings were performed through a small hole in the skull after at least $10 \mathrm{~d}$ of recovery. Extracellular single-unit recordings and local field potentials (LFPs) were obtained from the monocular region of V1. Single unit activity for most cells was studied using finediameter $(40 \mu \mathrm{m})$ quartz-insulated platinum/tungsten electrodes tapered and sharpened to a fine tip (impedance, 1.5-3 $\mathrm{M} \Omega$ ). A group of seven such electrodes was chronically implanted in a concentric array ( $\sim 200 \mu \mathrm{m}$ separation), with tips initially located just above the dura. Each of these electrodes was independently controlled by a miniature microdrive (Swadlow et al., 2005). Multiunit activity from superficial layers of the superior colliculus (SC) was simultaneously recorded by a similar three-channel microdrive system. A small number of cells were studied using 16-channel silicone probes, with recording site diameters of $33 \mu \mathrm{m}$ (NeuroNexus Technologies). Two stimulating electrodes (parylene-c insulated platinum/iridium micro wire) were implanted in LGN for identification of cortical neurons. Hippocampal EEG was recorded using two electrodes implanted above and below the CA1 layer and used, along with cortical EEG, for monitoring brain states. All electrophysiological activity was acquired using a Plexon data acquisition system.

\section{Brain state verification}

All data were recorded when subjects were fully awake. During recordings, no anesthetic agents were applied, the eyes were open, and subjects responded to external stimuli (novel sound and gentle touch, etc.). Some nonperiodic sensory stimulation (random sounds, tactile stimulation, movements in room) is often required to keep rabbits from transitioning from the awake, nonalert state to sleep (early signs of which are indicated by cortical spindle activity), and such stimulation was applied when needed. In some cases, when rabbits became drowsy during extended recordings, we provided novel sounds to generate alertness. If they were difficult to arouse, we let them sleep for a while, and did not collect data during these periods. After recording, the hippocampal EEG was segmented by visual inspection into alert versus nonalert states based on the presence of theta activity $(5-7 \mathrm{~Hz})$ or high-voltage, irregular activity, respectively (Swadlow and Gusev, 2001; Bezdudnaya et al., 2006; Cano et al., 2006; Stoelzel et al., 2009; Bereshpolova et al., 2011). During recording sessions, the average percentages of time the animals spent in the alert state and nonalert state were $32.94 \pm 1.36 \%$ and $36.28 \pm 2.20 \%$, respectively. Approximately $31 \%$ of the recording time was not classified as either state due to ambiguities in the EEG record. For some recorded files, comparisons between states were also performed using data around the alert/nonalert state transition points ( $5 \mathrm{~s}$ before and $5 \mathrm{~s}$ after).

\section{Cortical layer 4 identification}

Depth range of cortical layers was determined by electrode depth and reversal of stimulus-evoked field potentials that occur at known depths. Brief full-field flash-evoked LFPs were recorded at different depth. As previously verified histologically (Stoelzel et al., 2008), the top of layer 4 was identified as $100 \mu \mathrm{m}$ below a prominent current sink/source reversal point to the flash stimuli and the bottom of layer 4 was identified as 400 $\mu \mathrm{m}$ below the top of this layer. Only neurons within this narrow (400 $\mu \mathrm{m})$ depth zone were included in this study.

\section{Cell classification}

Classification of cortical layer 4 cells follows the criteria previously published (Zhuang et al., 2013). Layer 4 SINs were defined by responding to thalamic electrical stimulation with a high-frequency discharge of three or more spikes with peak frequencies of $>600 \mathrm{~Hz}$ (Swadlow, 1988, 1989, 1991, 1995, 2003), whereas layer 4 simple cells were defined by possessing a RF with one, two, or three spatially separated ON and/or OFF subfields. Layer 4 cells that did not meet either criterion were classified as "other" and were excluded from further analysis.

Cortical layer 4 simple cells and SINs were further classified into sustained/transient categories (Zhuang et al., 2013). The cell's response to optimal flashing stationary stimuli ( $1 \mathrm{~s}$ on $1 \mathrm{~s}$ off, or $2 \mathrm{~s}$ on $2 \mathrm{~s}$ off) during alert state was recorded. Then a sustained index (SI) was calculated as the ratio between the cell's maintained response (firing rate within $0.5-1.0 \mathrm{~s}$ after the onset of stimuli) and the baseline activity (firing rate within either -1 to 0 or -0.5 to $0 \mathrm{~s}$ relative to the onset of stimuli). Cells with SIs larger than 2 and with an absolute maintained response of $>1 \mathrm{spk} / \mathrm{s}$ were defined as sustained cells, whereas cells with SIs lower than 2 were defined as transient cells. Cells that failed to reach these criteria (SI larger than 2 but the absolute maintained activity lower than $1 \mathrm{spk} / \mathrm{s}$ ) remained as "sustained/transient unclassified". For some cells, responses to flashing stimuli during the nonalert state were also recorded to measure state effects, but only responses recorded during the alert state were used to classify the sustained/transient property.

\section{Visual stimulation and eye movement control}

Visual stimulation protocols were similar to those published previously (Zhuang et al., 2013). All visual stimuli were presented by a CRT monitor (Nec MultiSync, $40 \times 30 \mathrm{~cm}$, mean luminance, $48 \mathrm{~cd} / \mathrm{m}^{2}$, refresh rate: $160 \mathrm{~Hz}$ ). First, the cell's ON-OFF subfields were mapped with sparse noise stimulation by reverse correlation. After mapping, the RF center was constantly tracked by dynamic calculation of RF position from multiunit recordings in the SC. Second, the cell's sustained/transient property was measured with flashing stationary stimuli, which were optimized to elicit the strongest response possible. Third, circular drifting gratings were used to further measure the cell's response properties in both the alert and the nonalert states. The drifting grating was optimized by orientation, spatial frequency, temporal frequency, size, and contrast. The measurements were restricted to periods of time with stable eye position $\left(< \pm 1^{\circ}\right)$, verified by both the RF position of multiunit recordings in the SC and movies of eye position using a high-frequency infrared camera. Fourth, the cell's tuning properties were measured by pseudorandomly varying one of the four (orientation, spatial frequency, temporal frequency, or contrast) grating parameters while keeping the other four at the optimal values. Each presentation of a particular parameter combination lasted for 3-8 s with $2 \mathrm{~s}$ gaps in between and all tested parameter combinations were presented for at least 100 periods. During tuning property testing, the rabbit's eye position was constantly monitored and data before and after eye movements was discarded in offline analysis (Zhuang et al., 2013). Note that the sample sizes of individual tests are smaller than our total cell populations. Indeed, only a few cells were recorded for a period of time long enough to successfully finish all tests (which took several hours). For some cells, the spontaneous activity was also recorded for at least $10 \mathrm{~min}$ with the monitor screen set at a midluminance level. Only cells (27 simple cells and 17 SINs) with enough recordings for spontaneous activity $(>10 \mathrm{~min})$ were included in the analysis of $\mathrm{F} 0$ responses (without spontaneous activity) and $\mathrm{F} 1 / \mathrm{F} 0$ ratios with removal of spontaneous activity (see Results).

\section{Offline data analysis}

The offline data analysis methods have been reported earlier (Zhuang et al., 2013), and are described only briefly here. The cell's response PSTHs (peristimulus time histograms) to optimal flashing stimuli were used to calculated response latency which was defined as the time at which the smoothed function (smoothed by a sliding boxcar filter with width of 30 $\mathrm{ms}$ ) first passed $40 \%$ of its maximum value (Jin et al., 2011). The mean firing rates, $\mathrm{F} 0$ responses (mean firing rates - spontaneous firing rates), F1 responses (first harmonic component of the PSTHs), F1/F0 ratios with and without spontaneous activity (Chen et al., 2009) and Fano factors were calculated from the cell's response to the optimal drifting grating. All the tuning properties were analyzed in the same way as previously described (Zhuang et al., 2013). The F1 response was used to measure tuning properties for simple cells and the mean firing rates to measure tuning properties for SINs. The response amplitude for all tuning curves $\left(R_{\mathrm{con}}, R_{\mathrm{or}}, R_{\mathrm{SF}}, R_{\mathrm{TF}}\right)$, were calculated as the range between 


\section{A}

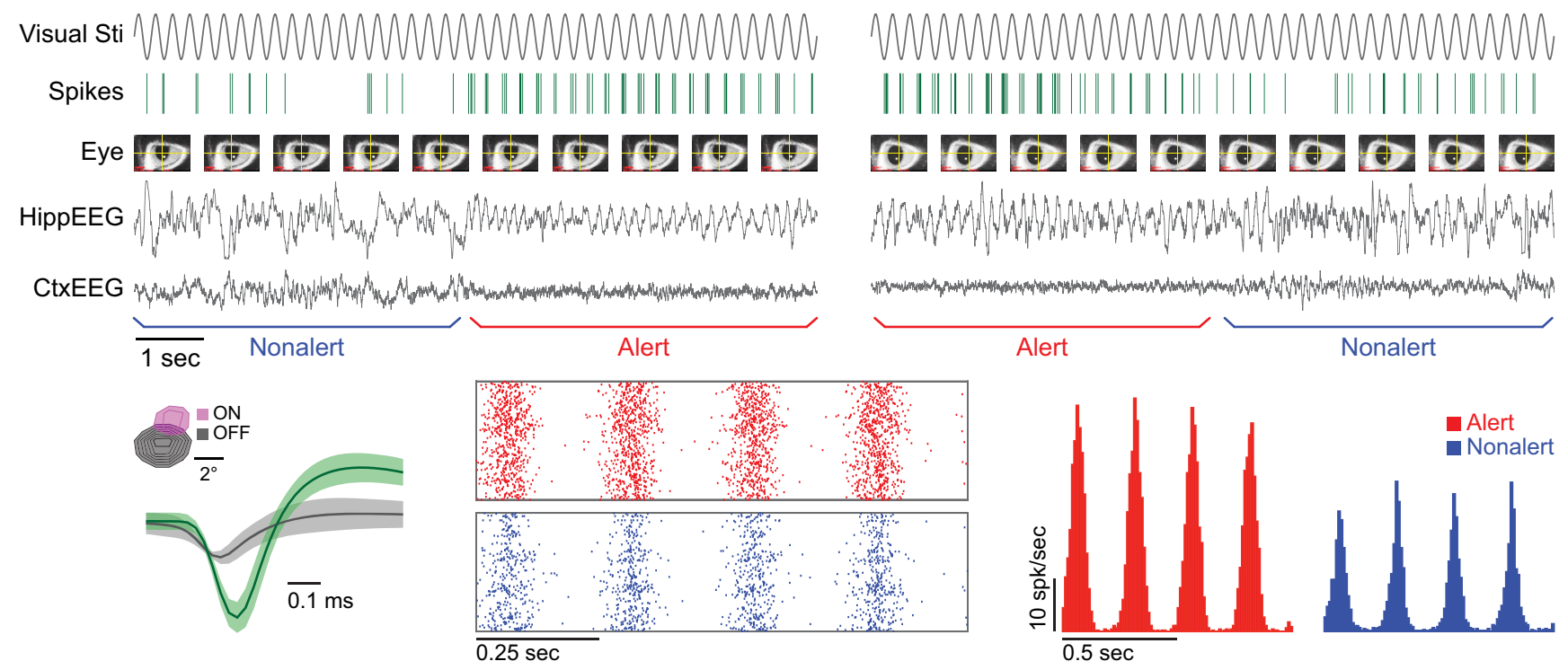

B

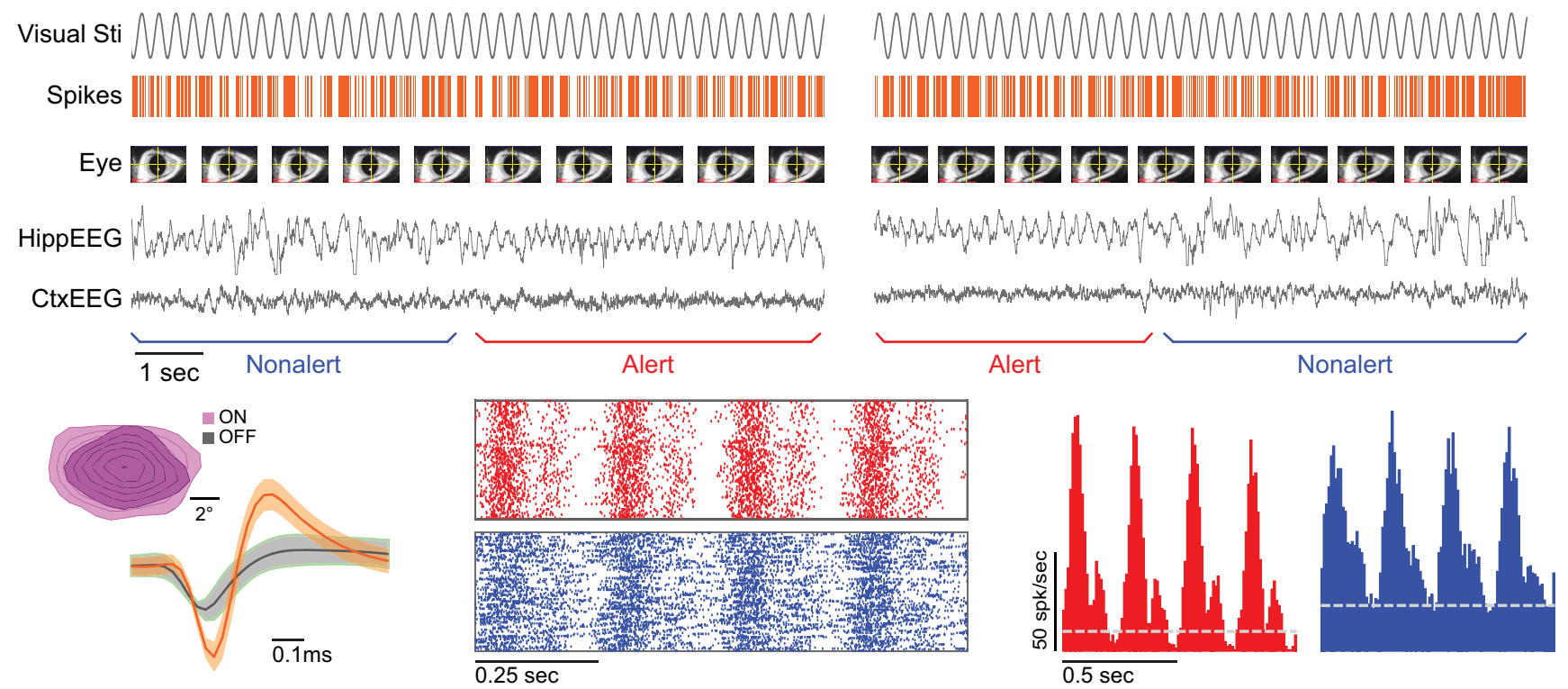

Figure 1. Responses to optimal drifting gratings of a layer 4 simple cell and a layer 4 SIN during alert/nonalert transitions. $\boldsymbol{A}$, Simple cell. $\boldsymbol{B}$, SIN. For each cell, one transition from the nonalert state to the alert state (top left), one transition from the alert state to the nonalert state (top right), spike waveform (bottom left, inset: receptive subfield map), peri-event rasters (lower middle), and PSTHs (bottom right) around transition points (from $\sim 5 \mathrm{~s}$ before to $\sim 5 \mathrm{~s}$ after) are shown. For each state transition example, from top to bottom, visual stimulation time course, the cells' spike response, snap shots of eye movie (every second), HippEEG, and CtxEEG are shown. For spike waveforms, green and orange traces: cell spikes; black traces: background hash activity; shaded areas: SD. For receptive subfield maps, each contour: 10\% of maximum activity. For rasters and PSTHs, four stimulation cycles are shown. Dashed gray line: spontaneous activity level (spontaneous level of the simple cell is too low to indicate with a dashed line).

baseline and the maximum response. Orientation tunings were fitted by von Mises distribution functions (Nowak et al., 2008). The orientation/ direction selectivity was measured by circular variance (CirVar), orientation selectivity index (OSI), and direction selectivity index calculated as $1-\left|\left(\sum \mathrm{R}_{\mathrm{j}} \mathrm{e}^{\mathrm{i} 2 \theta_{\mathrm{j}}}\right) / \sum \mathrm{R}_{\mathrm{i}}\right|,\left(\mathrm{R}_{\text {pref }}-\mathrm{R}_{\text {orth }}\right) /\left(\mathrm{R}_{\text {pref }}+\mathrm{R}_{\text {orth }}\right)$, and $\left(\mathrm{R}_{\text {pref }}-\mathrm{R}_{\text {oppo }}\right) /$ $\left(\mathrm{R}_{\text {pref }}+\mathrm{R}_{\text {oppo }}\right)$, respectively, where $R_{j}$ and $\theta_{j}$ represent the cells response (spk/s) and the angle (in radians) of $j^{\prime}$ th direction, respectively; $R_{\text {pref }}$ represents the cell's response in the preferred direction; $R_{\text {orth }}$ represents the cell's mean responses of the two directions orthogonal to the preferred direction; and $R_{\text {oppo }}$ represents the cell's response to the opposite of the preferred direction. Orientation tuning width was measured by the half-width at half-height (OR_HWHH) after removal of baseline. Contrast tuning response functions were fitted by a hyperbolic model with
(Peirce, 2007) or without (Albrecht and Hamilton, 1982) modification to account for high-contrast suppression. $\mathrm{C}_{50}$ was defined as the contrast at which the cell's response first reaches the middle point of the range from baseline to maximum response. Spatial frequency tuning curves were fitted by Gaussian function, from which peak spatial frequency (SF_peak) and spatial frequency tuning width at half maximum (SF_width) were extracted on logarithmic scale (with base 10). Temporal frequency tuning curves were fitted by Gaussian model on logarithmic scale (with base 2), from which peak temporal frequency (TF_peak) and temporal frequency tuning width (TF_width) at half maximum without baseline were extracted. All these measurements were done for both alert and nonalert state. All the models used here faithfully described the tuning properties of the cells' responses $\left(R^{2}\right.$, alert: $93.0 \pm 0.8 \%$; nonalert: $93.7 \pm$ 
A F0 responses

B
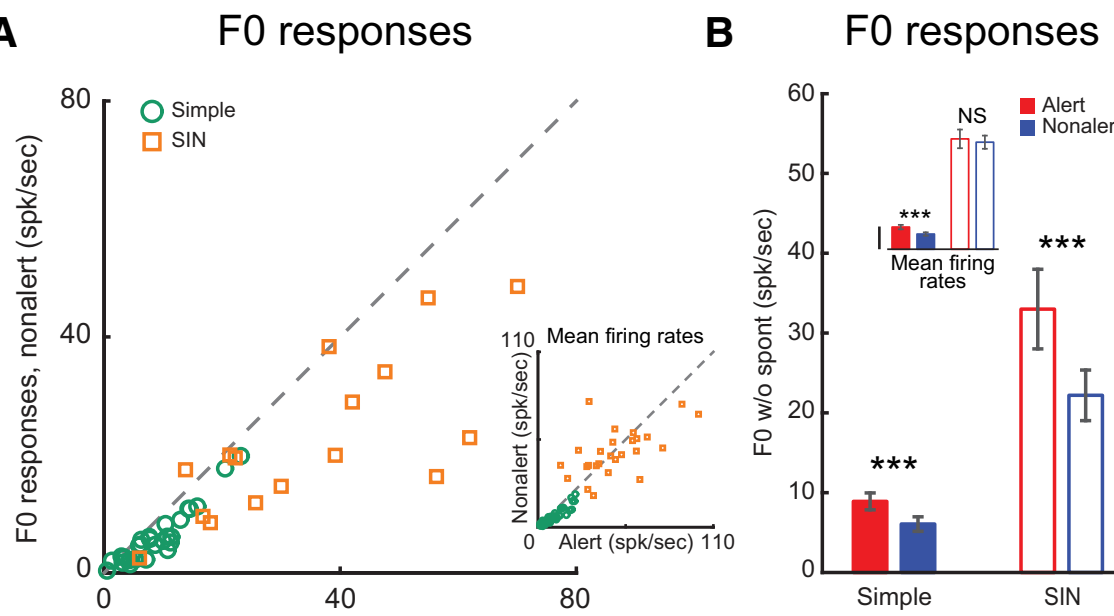

F0 responses, alert (spk/sec)

\section{C}

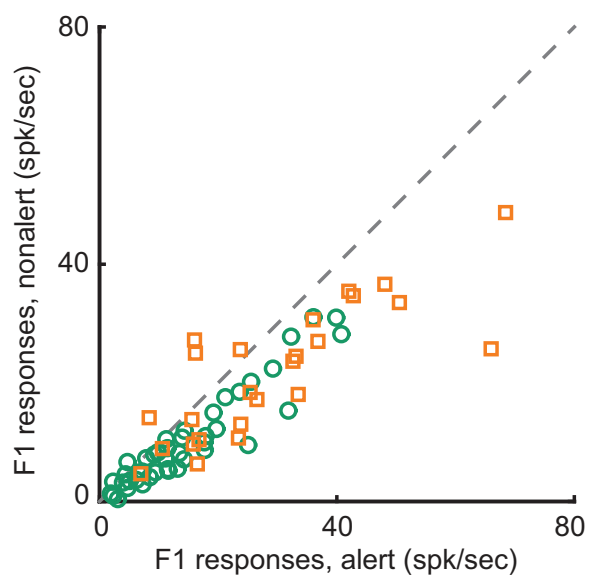

D

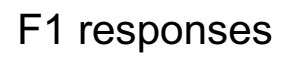

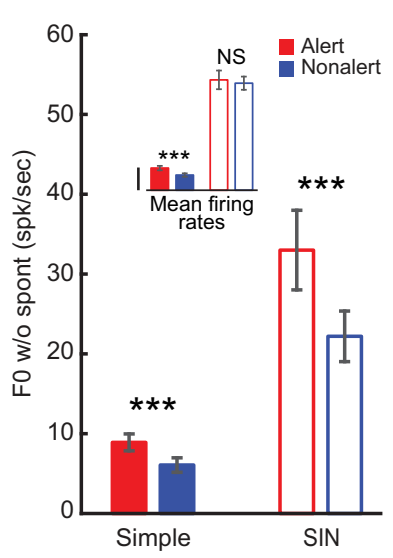

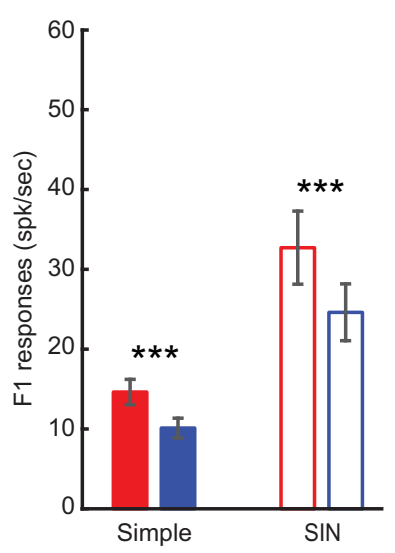

Figure 2. Alertness increases both $\mathrm{F} 0$ and $\mathrm{F} 1$ responses of layer 4 simple cells and layer 4 SINs. A, Scatter plot of F0 responses for each cell in the two states. Inset, Scatter plot of mean firing rates ( $F 0+$ spontaneous firing rate). $\boldsymbol{B}$, Population statistics of state effect on F0 responses. Inset, Population statistics of mean firing rates. Vertical calibration: $10 \mathrm{spk} / \mathrm{s}$. C, D, Scatter plot and population statistics for $\mathrm{F} 1$ responses, respectively. ${ }^{* * *} p<0.001 ; \mathrm{NS}, p>0.05$; paired $t$ test.

$0.7 \%)$. Only the fittings with $R^{2}$ values larger than 0.5 were included in data analysis. Cells not meeting this criterion included 2 of 27 simple cells for contrast response function, 5 of 13 SINs for orientation tuning, 1 of 21 SIN for spatial frequency tuning, and 2 of 18 SINs for temporal frequency tuning.

\section{Model simulation}

In the population coding model, eight layer 4 simple cells were simulated. These simulated cells had orientation tuning curve shapes matching the simple cell population average tuning measured in both states from recorded data but with preferred direction every $45^{\circ}$ apart (see Fig. $10 A, B$ ). When stimulated under certain direction (see Fig. 10A, magenta arrow), each simulated cell generated a spike train through a Gamma process parameterized by mean firing rate and Fano factor [interspike interval distribution $\sim \Gamma$ (1/Fano, Fano/Rate); Nawrot et al., 2008]. The mean firing rate was given by the representation of the stimulus in the orientation-tuning curve of each cell and the Fano factor by the average Fano factor measured in simple cells during either the alert (0.88) or the nonalert states (1.31). Then the simulated firing rates calculated from each spike train within a certain integration time window were fed to a direction detector. The direction detector integrated the firing rates from all eight simulated simple cells and performed a vector sum, the vector angles being the preferred directions of the cells and the vector modules the mean rates of each spike train for a given integration time. This vector sum (simulated vector sum) was matched to the vector sums calculated in the same way but from the original tuning curves (tuning curve vector sum). The detector then compared this vector sum (simulated vector sum) with a series of vector sums calculated in the same way but from the original tuning curves at different directions (tuning curve vector sum). The direction that gave the smallest distance between the simulated vector sum and the tuning curve vector sums was defined as the detected direction (Fig. 10A, green arrow). The absolute value of the difference between the stimulus direction and the detected direction (see Fig. 10A, detection error) were measured to evaluate the performance of the system. We simulated the relationship between the integration time and the detection error for three stimulus directions $(22.5,11.25$, and $0^{\circ}$, respectively; see Fig. $10 C-E$ ). For each stimulating direction, the detection error was calculated as the average over 1500 trials, and the integration time ranged from 0 to 2 seconds with steps of every $20 \mathrm{~ms}$.

\section{Results}

In total, 50 layer 4 simple cells and 30 layer 4 SINs in V1 of four adult female rabbits were recorded long enough to study alert/ nonalert state effects for at least one response property. SINs were defined by responding to thalamic electrical stimulation with a high-frequency discharge of three or more spikes with peak frequencies of $>600 \mathrm{~Hz}$ (Swadlow, 1988, 1989, 1991, 1994, 1995, 2003), whereas layer 4 simple cells were defined by possessing a RF with one, two, or three spatially separated $\mathrm{ON}$ and/or OFF subfields. No cell met both criteria (Zhuang et al., 2013), and cells which failed to meet either criterion were classified as other and were excluded from further analysis. All data were obtained when animals were head-fixed and awake. Wakefulness was further divided into alert and the nonalert states based on hippocampal, and in most cases, neocortical EEG (Swadlow and Gusev, 2001; Bezdudnaya et al., 2006; Cano et al., 2006; Stoelzel et al., 2009; Bereshpolova et al., 2011).

\section{Alertness increases responsiveness in layer 4}

Our previous studies demonstrated that LGN cells are more visually responsive during the alert state (Bezdudnaya et al., 2006; Cano et al., 2006). Here, we studied the effect of these changes in brain state at the main input layers of V1. V1 layer 4 cells were stimulated with optimal drifting gratings (optimized for contrast, orientation, spatial/temporal frequency for each cell), as awake animals transitioned between alert/ nonalert states. The effect of alertness was measured in both layer 4 simple cells (Fig. 1A) and layer 4 SINs (Fig. 1B). During the transitions between brain states, we studied the visual responses to a drifting grating during periods with highly stable eye position ( $\pm 1^{\circ}$; Fig. 1$)$. During the alert state, there was prominent hippocampal theta activity (HippEEG) and cortical desynchrony (CtxEEG), which changed to hippocampal high voltage irregular activity and cortical synchrony, during the nonalert state, and the transitions between alert and non- 
alert states occurred very quickly (in $\sim 1-2$ s; Fig. 1). No differences in neuronal response modulations between the two state transition directions (Fig. 1 left, nonalert to alert; Fig. 1 right, or alert to nonalert) were found, so most comparisons were made between alert and nonalert states, independently of the transition direction.

When rabbits became alert, both simple cells and SINs showed significantly stronger F1 (modulated responses) and F0 (mean firing rate minus spontaneous activity) responses to optimal drifting gratings (alert vs nonalert, simple F0: $8.9 \pm 1.1$ vs $6.1 \pm 0.9 \mathrm{spk} / \mathrm{s}, n=27, p<$ 0.001 ; simple F1: $14.6 \pm 1.6$ vs $10.1 \pm 1.2$ spk/s, $n=43, p<0.001$; SIN F0: $33.0 \pm$ 5.0 vs $22.2 \pm 3.2 \mathrm{spk} / \mathrm{s}, n=17, p=0.008$; SIN F1: $32.7 \pm 4.6$ vs $24.6 \pm 3.6 \mathrm{spk} / \mathrm{s}, n=$ 26, $p<0.001$; Fig. 2). The same results were found when our analysis was limited to brief time periods $(\sim 5 \mathrm{~s})$ before and after the state transitions (alert vs nonalert, simple F0: $8.5 \pm 1.1$ vs $6.5 \pm 1.0$ $\mathrm{spk} / \mathrm{s}, n=26, p<0.001$; simple F1: $14.6 \pm$ 1.6 vs $10.1 \pm 1.2 \mathrm{spk} / \mathrm{s}, n=30, p<0.001$; SIN F0: $35.6 \pm 4.6$ vs $26.3 \pm 3.2, n=14$, $p=0.005 ;$ SIN F1: $24.4 \pm 4.1$ vs 17.9 vs 2.7 spk/s, $n=18, p=0.008)$. However, if spontaneous activity was not subtracted, the net effect of alertness on SINs' mean firing rates was very diverse (Fig. $2 A$, inset; and Fig. 4).

\section{Alert/nonalert state does not affect}

linearity of spatial summation in layer 4 F1/F0 ratios are a common measurement of spatial summation linearity for visual cortical cells. We previously showed that layer 4 simple cells are much more linear than SINs (Zhuang et al., 2013). Here we found that, despite this difference, the alertness did not affect spatial summation linearity for either layer 4 simple cells or layer 4 SINs after removal of spontaneous activity (F1/F0 ratios; alert vs nonalert, simple: $1.61 \pm 0.05$ vs $1.65 \pm 0.03, n=27, p=$ 0.065 ; SIN: $0.83 \pm 0.12$ vs $0.84 \pm 0.12, n=17, p=0.71$; Fig. $3 A, B)$. The same results can also be found from the data around brief time periods $(\sim 5 \mathrm{~s})$ before and after the state transitions ( \pm 5 s, simple: $1.61 \pm 0.05$ vs $1.63 \pm 0.04, n=26, p=0.288$; SIN: $0.855 \pm 0.14$ vs $0.884 \pm 0.13, n=15, p=0.305$ ). Thus, both layer 4 simple cells and SINs keep their spatial summation linearity constant when the animal switches brain states.

\section{Alertness made visual responses in layer 4 not only stronger but also more reliable}

The cycle by cycle response reliability was measured by the Fano factor. Both layer 4 simple cells and SINs strongly increased their response reliability during the alert state (Fano factor, alert vs nonalert, simple: $0.88 \pm 0.07$ vs $1.31 \pm 0.11, n=30, p<0.001$; SIN: $0.87 \pm 0.08$ vs $1.71 \pm 0.09, n=18, p<0.001$; Fig. $3 C, D)$, a finding that could be replicated in brief time periods $(\sim 5 \mathrm{~s})$
F1/F0 w/o spont

B F1/F0 w/o spont

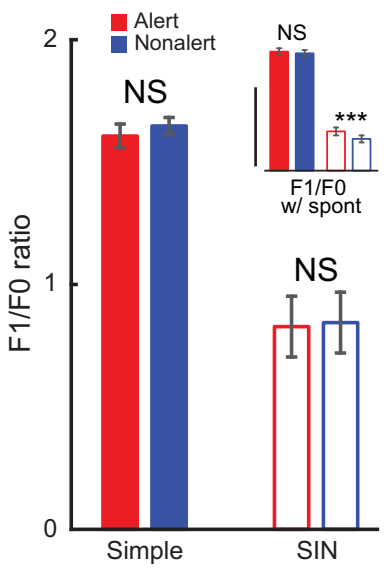

F1/F0 w/o spont alert
Fano

D

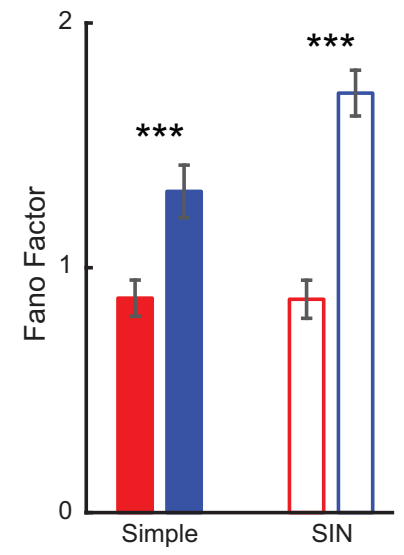

Fano factor alert

Figure 3. Alertness does not affect spatial summation linearity (F1/F0 ratios) but significantly increases response reliability (decrease Fano factor) in both layer 4 simple cells and layer 4 SINs. $A$, Scatter plot of F1/F0 ratios after removal of spontaneous statistics of both states for each cell. Inset, Scatter plot of F1/F0 ratios with spontaneous activity retained. $\boldsymbol{B}$, Population spontaneous activity retained. Vertical calibration: 1. C, Scatter plot of Fano factors during both states for each cell. Inset, Scatter plot and population statistics of Fano Factors for LGN concentric cells. D, Population statistics of state effect on Fano factor. ${ }^{* * *} p<$ $0.001 ;{ }^{*} p<0.05 ; \mathrm{NS}, p>0.05$; paired $t$ test.

around state transitions (alert vs nonalert, simple: $0.90 \pm 0.08$ vs $1.18 \pm 0.09, n=30, p<0.001$; SIN: $1.18 \pm 0.29$ vs $1.60 \pm 0.18$, $n=18, p<0.001)$. Interestingly, the increase in response reliability was more than two times higher in cortical layer 4 neurons than in the LGN inputs (percentage of Fano factor increase in the nonalert state, simple: $33.71 \pm 2.31 \%, n=30$; SIN: $49.37 \pm$ 3.06\%, $n=18$; LGN: $15.74 \pm 5.73 \%, n=11$; simple vs LGN: $p=$ 0.0012; SIN vs LGN: $p<0.001$, independent $t$ test; Fig. $3 C$, inset). This finding indicates that the effect of alertness on response reliability is not simply transmitted from LGN but is amplified in visual cortex.

\section{Contribution of spontaneous activity to state effects}

Although layer 4 simple cells have very low levels of spontaneous activity, which are little affected by alertness, layer 4 SINs have very high spontaneous activity, which usually decrease significantly during the alert state (Bereshpolova et al., 2011; Zhuang et al., 2013). As described in methods, in our analyses of the "F0" 
A

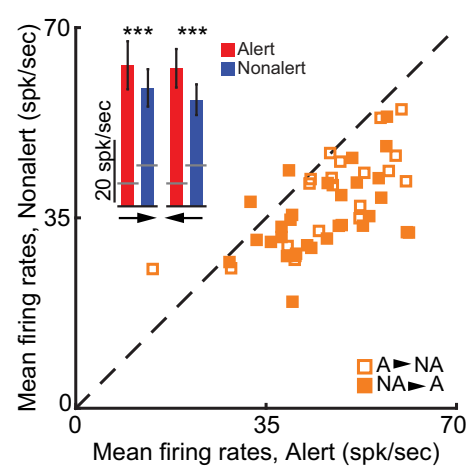

B

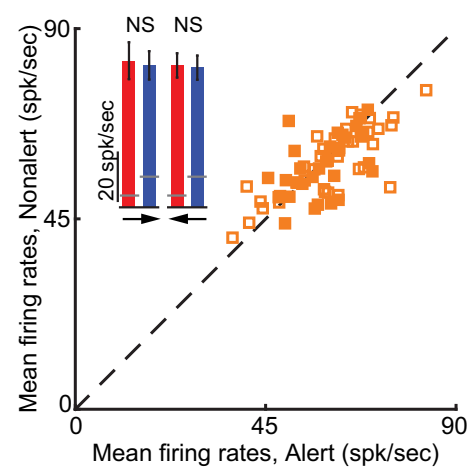

C

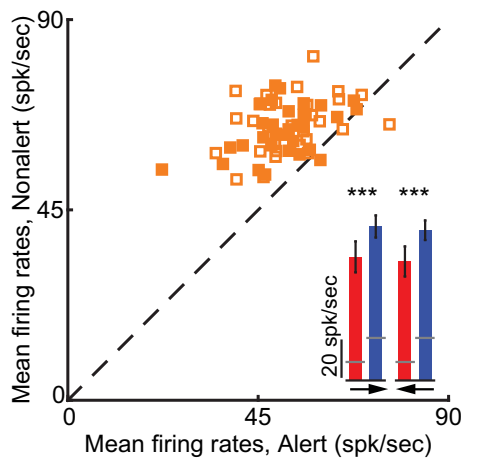

Figure 4. The state effects on mean firing rates are diverse for different SINs, but consistent and reliable for individual SINs. For three example SINs ( $\boldsymbol{A}-\boldsymbol{C}$ ), the mean firing rates (F0 responses plus spontaneous firing rates) in both states around state transitions ( $5 \mathrm{~s}$ before $5 \mathrm{~s}$ after) are shown. For each panel, every filled square represents an individual state transition from the nonalert state to the alert state and every open square represents an individual state transition from the alert state to the nonalert state. $A, A$ SIN has constantly higher mean firing rates during the alert state than during the nonalert state. $\boldsymbol{B}, A$ SIN has about the same mean firing rates during both states. $\boldsymbol{C}$, A SIN has constantly lower mean firing rates during the alert state than during the nonalert state. Insets, Mean firing rates in each state of each type of transition points for the particular cell. Gray lines indicate spontaneous firing rates. Arrow at the bottom shows the direction of state transition (left to right $=$ alert to nonalert; right to left $=$ nonalert to alert). Vertical calibration: $20 \mathrm{spk} / \mathrm{s} .{ }^{* * *} p<0.001 ; \mathrm{NS}, p>0.05$; paired $t$ test.

A

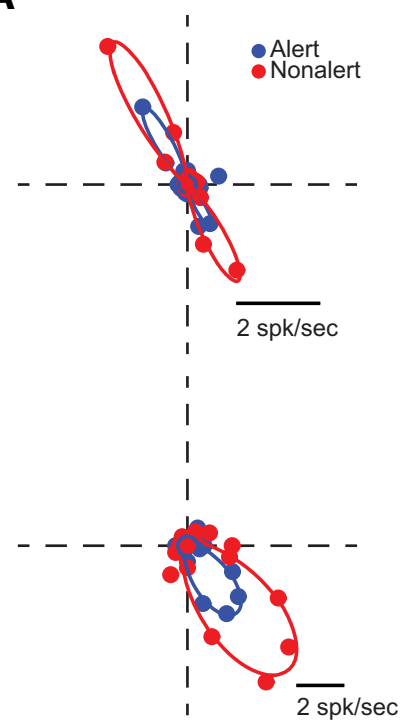

C
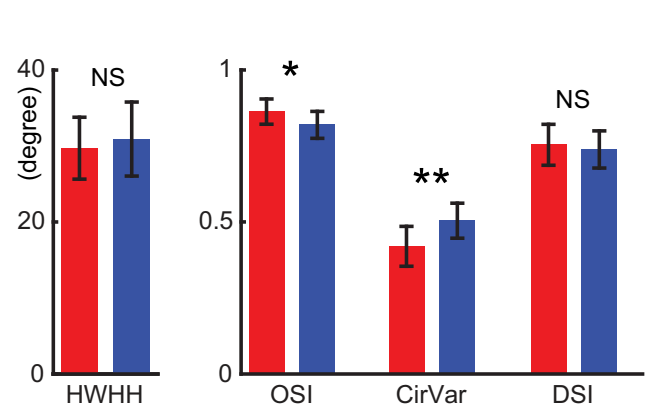

D

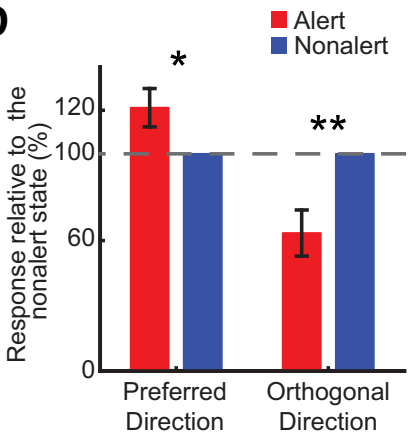

Figure 5. The state effects on orientation tuning of layer 4 simple cells. $A$, Orientation tuning curves of two example layer 4 simple cells. B, Population average of $\mathrm{F} 1$ orientation tuning curves of layer 4 simple cells. Tuning curves for each cell were normalized to the peak response (the bigger one of alert peak and nonalert peak) before averaging. Preferred direction (marked by arrow) for each cell are aligned as $0^{\circ}$. Two directions orthogonal to the preferred direction are marked by arrowhead. C, Population statistics of orientation tuning parameters during the alert and nonalert state. ${ }^{* *} p<0.01 ;{ }^{*} p<$ 0.05 ; NS, $p>0.05$; paired sample $t$ test. $\boldsymbol{D}$, Average F1 responses (normalized by the F1 responses during the nonalert state) of layer 4 simple cells in preferred direction and orthogonal directions. Dashed line: $100 \% .{ }^{* *} p<0.01 ;{ }^{*} p<0.05$; one sample $t$ test. response described above, the spontaneous firing rate of each cell was subtracted from the mean response rate to drifting grating stimuli. However, to investigate the contribution of spontaneous activity to state effects, we also measured state changes in mean firing rates and F1/F0 ratios without subtracting spontaneous activity. When the spontaneous activity was not subtracted in simple cells, alertness still significantly increased their mean firing rates (alert: $9.8 \pm 1.0$, nonalert: $6.7 \pm$ $0.7 \mathrm{spk} / \mathrm{s}, n=43, p<0.001$; Fig. $2 A, B$, insets) without changing their F1/F0 ratios (alert: $1.50 \pm 0.04$, nonalert: $1.48 \pm$ $0.04, n=43, p=0.25$; Fig. $3 A, B$, insets). However, when the spontaneous activity was not subtracted in SINs, their mean firing rates showed no significant difference between the two states (alert: $48.6 \pm$ 4.1 , nonalert: $47.1 \pm 2.9 \mathrm{spk} / \mathrm{s}, n=26, p=$ 0.68 ; Fig. $2 A, B$, insets) and their F1/F0 ratios became slightly higher during the alert state (alert: $0.50 \pm 0.05$, nonalert: $0.40 \pm 0.04, n=26, p<0.001$; Fig. $3 A, B$, insets), although still much lower than those of simple cells. Further analysis showed that the overall lack of state changes in the SIN mean firing rates was due to the diverse effects that alertness had on the SINs' mean spontaneous firing rates (Fig. 4). The effect of alertness on SINs could be an increase (Fig. $4 A$ ), no change (Fig. 4B), or decrease (Fig. 4C) of mean firing rate. Importantly, the effect was very reliable across trials for each SIN.

\section{Alert/nonalert state effects on orientation/direction tuning properties of simple cells}

Unlike SINs, layer 4 simple cells show strong selectivity for both the orientation 
and direction of motion (Zhuang et al., 2013). Because this orientation/direction selectivity plays an important role in visual cortical processing, it is important to investigate in what extent it is affected by brain state. Consistent with the results above, alertness significantly increased response amplitude of orientation/direction tuning curves of simple cells (alert vs nonalert, $R_{\text {or: }}: 19.2 \pm 4.3 \mathrm{vs} 17.5 \pm 4.2 \mathrm{spk} / \mathrm{s}, n=$ $17, p=0.03)$, but the shapes of orientation/ direction tuning curves were barely affected by states (Fig. $5 A, B$ ). Alertness did not affect the orientation tuning $\mathrm{HWHH}(29.7 \pm 4.1$ vs $30.9 \pm 4.9 \mathrm{deg}, p=0.42)$ and direction selectivity index (DSI; $0.75 \pm 0.07$ vs $0.74 \pm$ $0.06, p=0.47$; Fig. $5 C$ ). However, it caused a slight but significant improvement in orientation selectivity as measured by OSI $(0.86 \pm 0.04$ vs $0.82 \pm 0.04, p=0.015)$ and CirVar $(0.42 \pm 0.07$ vs $0.50 \pm 0.06, p=$ 0.008 ; Fig. $5 C$ ). The improvement in orientation selectivity was caused both by a response increase in the preferred direction (alert, nonalert: $1.21 \pm 0.09: 1, n=16, p=$ 0.03 ; one-sample $t$ test) and a response suppression in the directions orthogonal to preferred direction (alert, nonalert: $0.64 \pm$ $0.11: 1, p=0.004$; one-sample $t$ test; Fig. $5 B, D)$. These results demonstrate that alertness increases the strength of visual responses in simple cells without broadening their orientation/direction tuning. Importantly, alertness improves orientation selectivity by enhancing visual responses in the preferred direction and suppressing them in the orthogonal directions.

\section{Alert/nonalert state effects on the contrast response functions of simple cells}

Because of its effect on response strength, alertness had a multiplicative effect on the contrast response functions of simple cells (alert vs nonalert, $R_{\text {con }}: 18.8 \pm 2.8 \mathrm{vs} 15.9 \pm 2.5 \mathrm{spk} / \mathrm{s}, n=25, p<$ 0.001; Fig. 6). However, this multiplicative increase did not affect the contrast that generated half-maximum response $\left(\mathrm{C}_{50}: 26.6 \pm\right.$ $3.4 \%$ vs $28.6 \pm 3.2 \%, n=25, p=0.25$ ). As shown previously (Zhuang et al., 2013), some simple cells respond stronger at intermediate contrasts than at high contrasts. Here, we demonstrate that this high-contrast suppression is strongly affected by brain state (Fig. 6A,B). Whether the cell showed high-contrast suppression or not was decided by the best fit of the cell's contrast tuning curve (fit with or without high-contrast suppression). We used $R_{\text {nor }}{ }^{2}$ as the criterion for goodness of fitting to control for the additional parameter used in the fit with high-contrast suppression (Zhuang et al., 2013). This criterion allowed us to select contrast response functions with high signal-to-noise and limit the possibility of false positive identification of high-contrast suppression. In layer 4 simple cells that showed high-contrast suppression in either/both states $(n=15)$, the high-contrast suppression, calculated as the percentage of response suppression at the highest contrast relative to the maximum response, was nearly 2 times stronger during the alert state than during the nonalert
Single cell

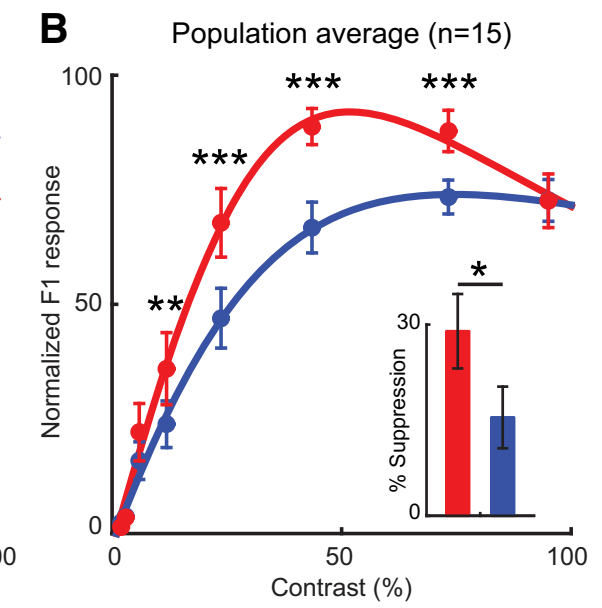

D

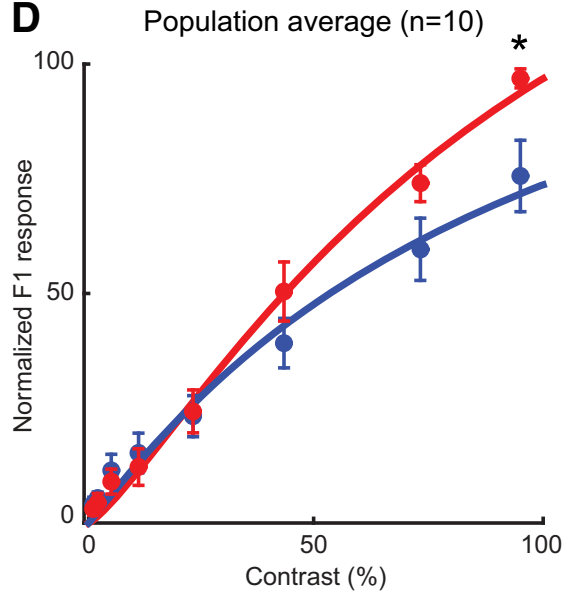

Single cell

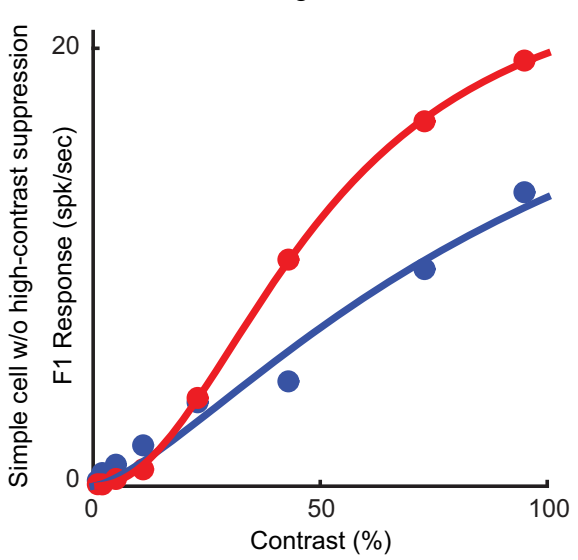

Contrast (\%)

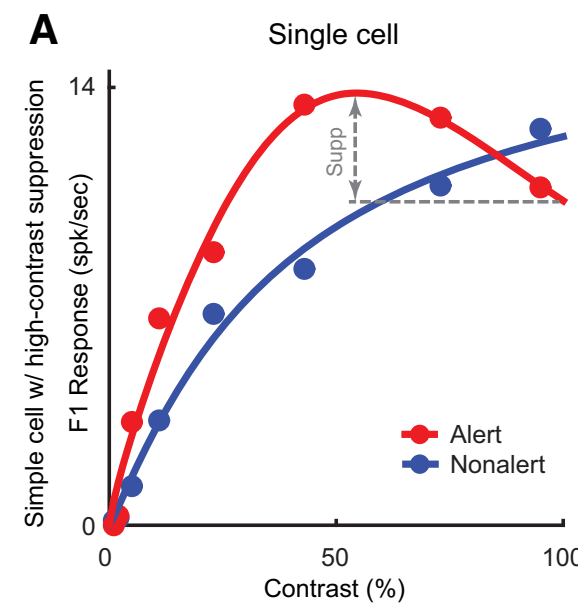

Figure 6. The state effects on contrast response function of layer 4 simple cells. $\boldsymbol{A}$, Contrast response function of an example layer 4 cell showing strong reduction of response at high contrast during the alert state but no reduction during the nonalert state. $B_{,}$ Werage percentage of reduction in both state for these simple cells. C, Contrast response function of an example layer 4 simple cell showing no high-contrast suppression during either state. $\boldsymbol{D}$, Population average of contrast response function of layer 4 simple cells which showed no high-contrast suppression in either state $(n=11) .{ }^{*} p<0.05 ;{ }^{* *} p<0.01$; ${ }^{* * *} p<0.001$; paired t test.

state (alert: $29.0 \pm 5.8 \%$; nonalert: $15.4 \pm 4.8 \%, n=15, p=$ 0.023; Fig. $6 B$ ). These results indicate that, in a subset of simple cells, the alert state selectively amplifies visual responses to intermediate contrasts. It should be noted that the proportion of simple cells showing high-contrast suppression (15 of 25 in our sample) may be underestimated due to limitations of CRT monitors in reaching the luminance levels and luminance contrasts that are found in natural scenes.

\section{Alert/nonalert state effects on spatial/temporal tuning properties of simple cells}

Alertness also had a multiplicative effect on the spatial tuning of simple cells (alert vs nonalert, $R_{s f}: 19.9 \pm 4.7$ vs $15.9 \pm 4.6, n=13$, $p<0.001$; Fig. $7 A$ ) without affecting the spatial tuning peak and width (SF_peak: $0.21 \pm 0.06$ vs $0.21 \pm 0.06 \mathrm{cpd}, p=0.48$; SF_width: $0.24 \pm 0.05$ vs $0.23 \pm 0.04$ oct, $p=0.85$; Fig. $7 B$ ). Therefore, the alert state increased the strength of visual responses in layer 4 simple cells without affecting their spatial selectivity. Alertness also had a multiplicative effect on the temporal tuning of simple cells $\left(R_{t}: 13.3 \pm 3.1\right.$ vs $10.5 \pm 2.5 \mathrm{spk} / \mathrm{s}, n=22$, $p=0.002$; Fig. 7C) and, as shown previously in LGN cells (Bezdudnaya et al., 2006), it made the temporal frequency tuning 


\section{A Spatial Frequency Tuning}
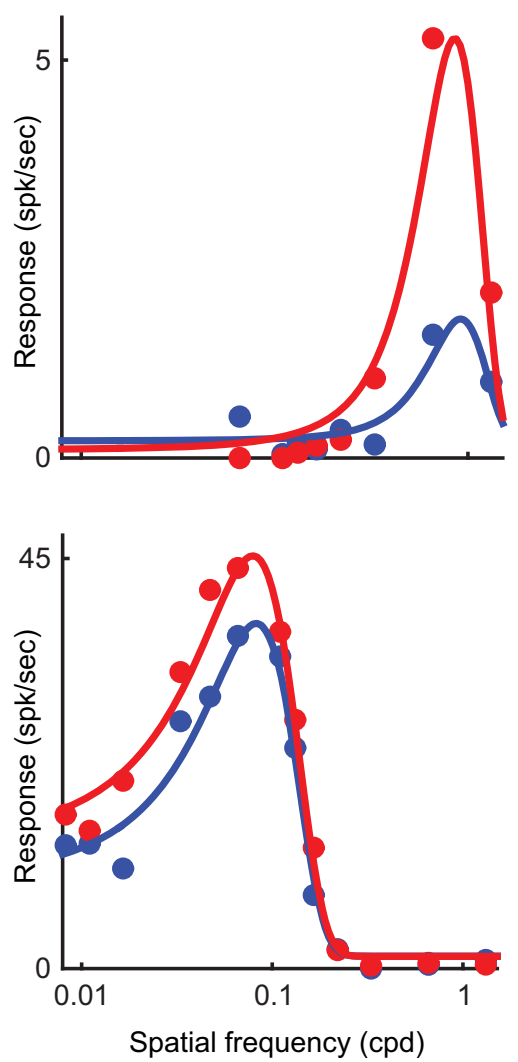

B
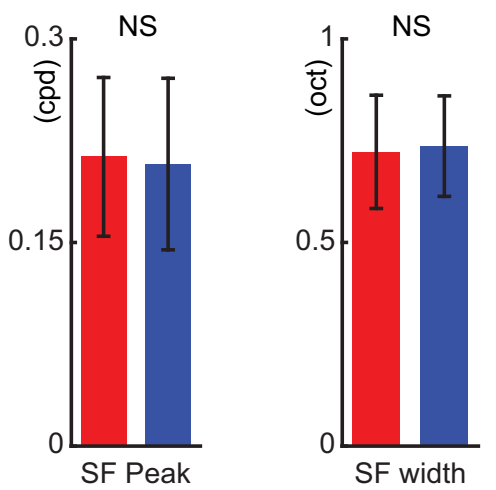

C Temporal Frequency Tuning
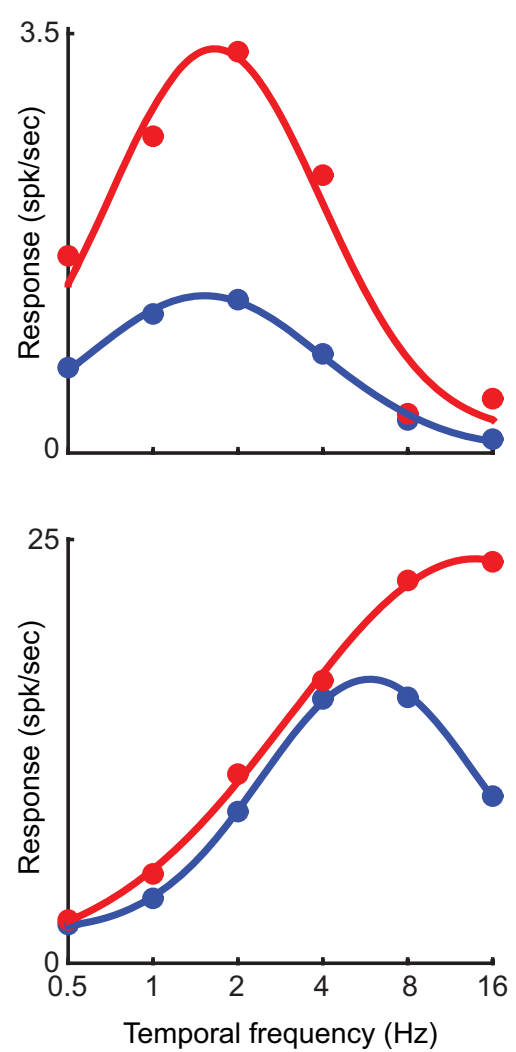

D

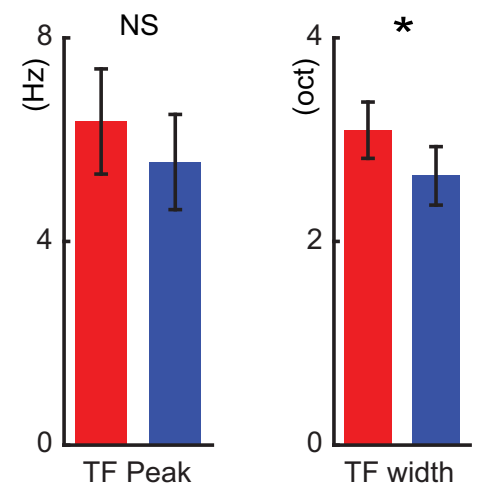

were no significant changes in orientation tuning (alert vs nonalert, HWHH: $71.1 \pm$ 7.8 vs $66.1 \pm 10.3 \mathrm{deg}, n=8, p=0.86$; OSI: $0.17 \pm 0.03$ vs $0.18 \pm 0.03, p=0.37$; CirVar: $0.95 \pm 0.02$ vs $0.94 \pm 0.02, p=0.12$; DSI: $0.15 \pm 0.03$ vs $0.14 \pm 0.03, p=0.37$ ), contrast response $\left(\mathrm{C}_{50}: 11.8 \pm 2.5 \%\right.$ vs $10.7 \pm$ $1.7 \%, n=22, p=0.41$; high-contrast suppression: $11.4 \pm 3.4 \%$ vs $8.5 \pm 3.6 \%, n=$ $12, p=0.268$ ), spatial tuning (SF_peak: $0.21 \pm 0.06$ vs $0.16 \pm 0.04 \mathrm{cpd}, n=20, p=$ 0.24 ; SF_width: $1.28 \pm 0.12$ vs $1.25 \pm 0.11$ oct, $p=0.70$ ), or temporal tuning (TF_ peak: $6.25 \pm 1.43$ vs $5.51 \pm 1.15 \mathrm{~Hz}, n=16$, $p=0.30$; TF_width: $4.55 \pm 0.56$ vs $3.98 \pm$ $0.45 \mathrm{oct}, n=16, p=0.47$ ). As noted above, alertness had diverse but very reliable effects on the spontaneous firing of different SINs (Fig. 4), and this diversity was reflected in their stimulus tuning functions (Fig. 8).

\section{Alert/nonalert state effects on sustained response to flashing stationary stimuli Both layer 4 simple cells and SINs can be di- vided into sustained and transient categories, based on their responses to flash- ing stationary stimuli (Zhuang et al., 2013). Because sustained responses of LGN cells (Swadlow and Weyand, 1985) and V1 effer- ent neurons (Swadlow and Weyand, 1987) are strongly affected by brain state, we ex- amined these effects in layer 4 . The alert state did not change the latency to flashing stimuli in layer 4 simple cells (alert vs non- alert, $43.7 \pm 4.4$ vs $41.6 \pm 3.1 \mathrm{~ms}, n=27$, $p=0.511)$ and SINs $(29.3 \pm 1.5$ vs $29.3 \pm$ $1.4 \mathrm{~ms}, n=12, p>0.9$ ). However, for both sustained simple cells and SINs, alertness significantly increased their sustained re- sponses (simple: $3.0 \pm 0.5 \mathrm{vs} 1.3 \pm 0.2 \mathrm{spk} / \mathrm{s}$, $n=20, p<0.001 ;$ SIN: $21.3 \pm 4.9$ vs $7.0 \pm$ $5.2 \mathrm{spk} / \mathrm{s}, n=6, p<0.001)$ and sustained indices (SI, simple: $39.4 \pm 15.2$ vs $4.9 \pm 0.4$, $p=0.034 ;$ SIN: $3.3 \pm 0.8$ vs $1.5 \pm 0.4, p=$ 0.008; Fig. 9).}

\section{Alertness can enhance computational speed of feature detection}

Effects of alertness on simple cells included an increase in response amplitude in preferred direction, enhanced response broader (TF_width: $3.1 \pm 0.3$ vs $2.6 \pm 0.3$ oct, $p=0.03$, Fig. $7 D$ ). There was also a slight increase in the temporal frequency peak during the alert state but, unlike in LGN (Bezdudnaya et al., 2006), it did not reach significance (TF_peak: $6.4 \pm 1.0$ vs $5.6 \pm$ $0.9 \mathrm{~Hz}, p=0.057$; Fig. $7 D$ ). It should be noted that all these tuning curves were measured from F1 responses, and therefore, the analysis was independent of their spontaneous activity.

\section{Alert/nonalert state effects on stimulus tuning properties of SINs}

Alertness enhanced response reliability of SINs even more than simple cells but did not affect many of its response properties. There reliability, and selective suppression to stimuli moving orthogonal to the preferred direction. To investigate the potential impact of these state effects on the speed of cortical processing, we constructed a population coding model of direction detection (Fig. $10 A, B)$. This model simulated eight simple cells with preferred directions separated by $45^{\circ}$ and tuning curve shapes matching the simple cell population average tuning measured in our data (Fig. $5 B$ ). Each of these cells generated spike responses when stimulated at certain direction (stimulating direction, magenta arrow in Fig. 10A). A direction detector then integrated the responses of all eight simulated cells within a certain integration time window 
A
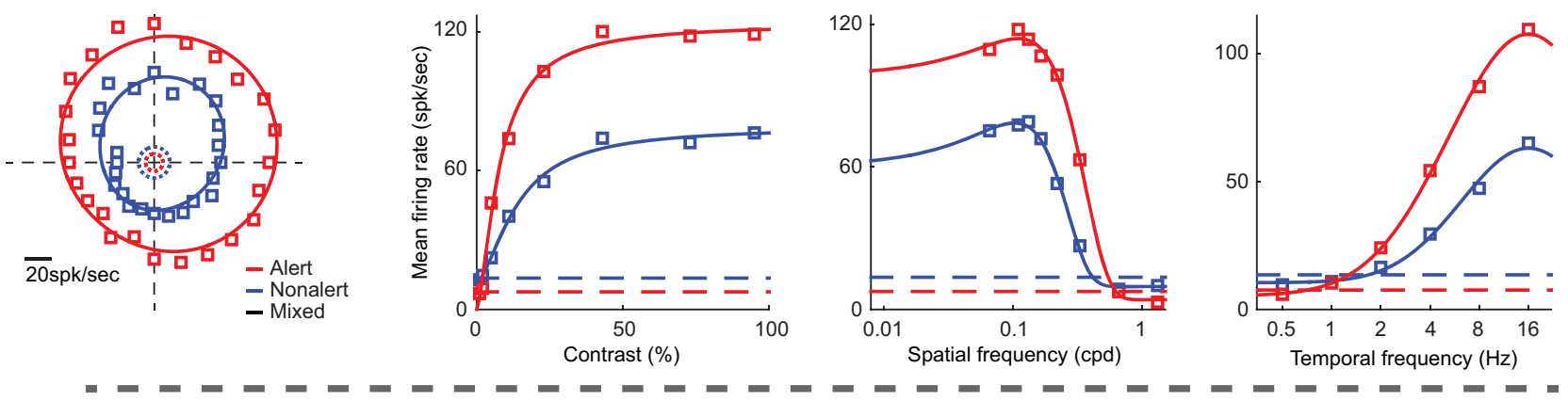

B
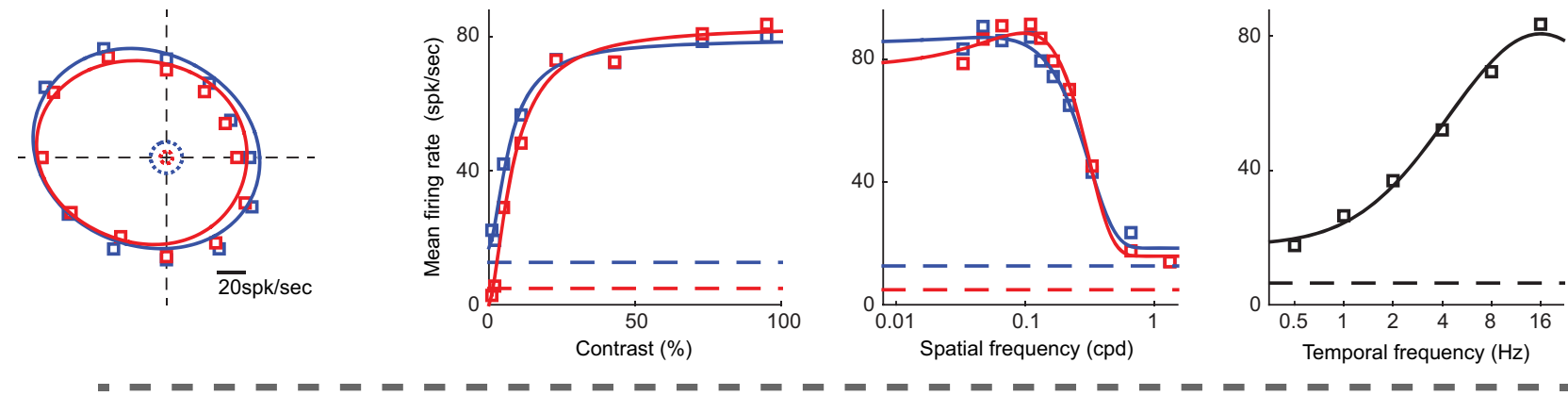

C

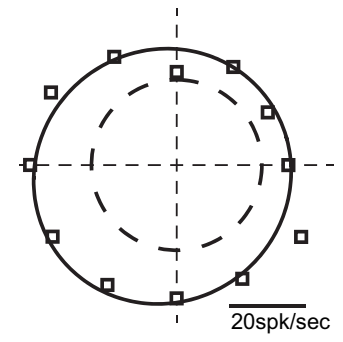

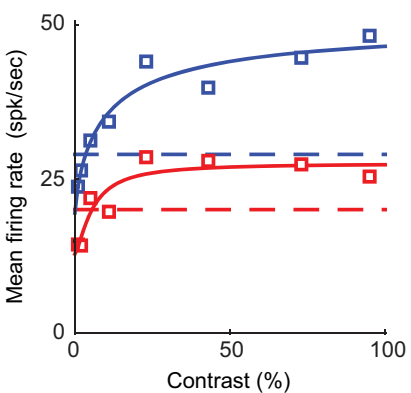
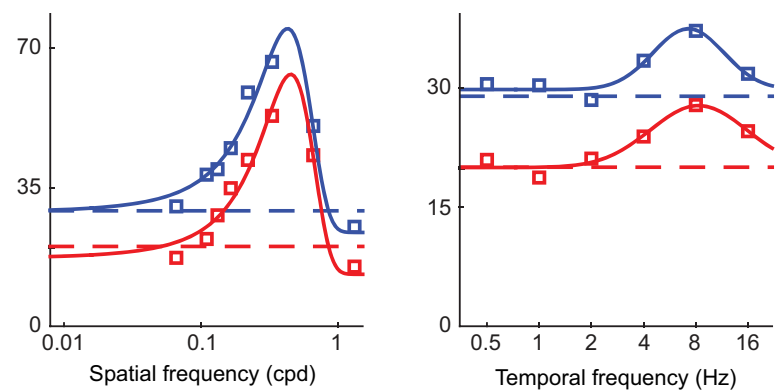

Figure 8. For three SINs $(\boldsymbol{A}-\boldsymbol{C})$, example tuning curves of orientation, contrast, spatial and temporal frequency (left to right) in both states. $\boldsymbol{A}$, A SIN shows constantly higher mean firing rates during the alert than during the nonalert state. $B, A$ SIN shows about the same mean firing rates during both states. $C, A$ SIN shows constantly lower mean firing rates during the alert state than during the nonalert state. Tuning curves in black represent data from mixed state (not enough to be cut into the alert/nonalert state). Dashed lines indicate spontaneous activity level.

to detect the stimulus direction (detected direction, green arrow in Fig. 10A). In this model, we made the direction tuning curves and the reliability (Fano factor) of simulated cells adjustable. To assess the contribution of each of the three effects of alertness mentioned above, we ran the simulation in four different conditions (Fig. 10C-E): (1) tuning curve shape and response reliability of alert state (A), (2) tuning curve shape and response reliability of nonalert state (NA), (3) tuning curve shape of nonalert state but the high reliability of alert state (nonalert high reliability; NA HR), and (4) tuning curve shape of nonalert state but scaled up to match the maximum response in alert state and high response reliability of alert state (nonalert scaled high reliability; NA HRS). From these four simulations, the three effects of alertness: high response reliability, increased response strength and selective suppression in the orthogonal direction can be estimated from the differences in detection time between NA and NA HR, between NA HR and NA HRS, and between NA HRS and A, respectively (Fig. 10E, square inset).

The results of these simulations demonstrate that the detection error decreases exponentially as the integration time becomes longer. Moreover, the three major effects of alertness play an important role in increasing the speed of cortical processing. If we use a detection error of $20^{\circ}$ as a threshold, the detection time was $457 \pm 12.9 \mathrm{~ms}$ during the NA state, $142 \mathrm{~ms}$ shorter if we increased response reliability to the level of alert state (NA, HR: $315 \pm 8.3 \mathrm{~ms}), 47 \mathrm{~ms}$ further shorter if we enhanced response strength to the level of alert state (NA HRS: $268 \pm 6.8 \mathrm{~ms}$ ), and 42 ms further shorter if we added the orthogonal-response suppression (A: $226 \pm 5.8 \mathrm{~ms}$ ). These results demonstrate that the alert state can increase the speed of cortical computation (i.e., compute stimulus direction) by $>200 \mathrm{~ms}$, a difference that could have an important behavioral impact (i.e., quickly escape in the opposite direction). Moreover, the results suggest that the most important factor in shortening computation speed is the increase in response reliability followed by the increase in response strength and orthogonal suppression.

\section{Discussion}

We demonstrated that changes in brain state have pronounced, cell-specific effects on the responses of neurons at the primary input layers of visual cortex. For simple cells, the alert state increased the strength and reliability of visual responses, made the temporal frequency tuning broader but preserved the contrast sensitivity, linearity of spatial summation and spatial frequency tuning. Moreover, alertness also selectively suppressed simple 
A

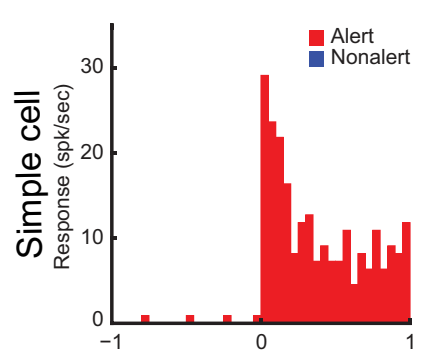

D

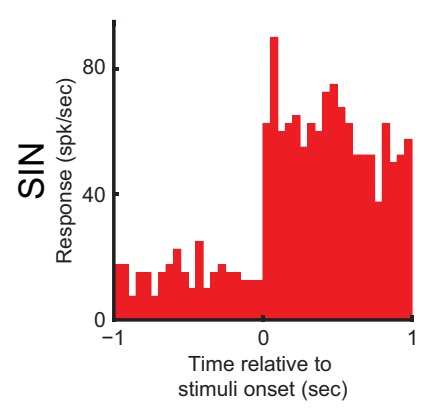

B

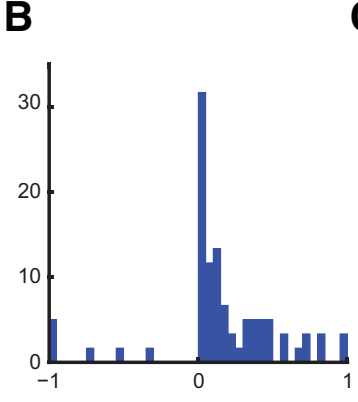

E

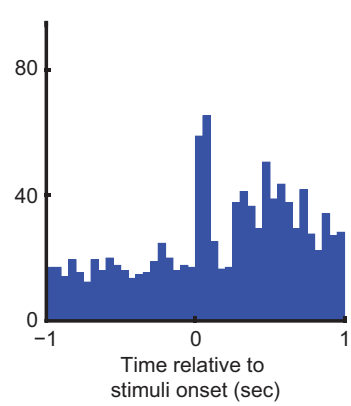

C All sustained simple cells

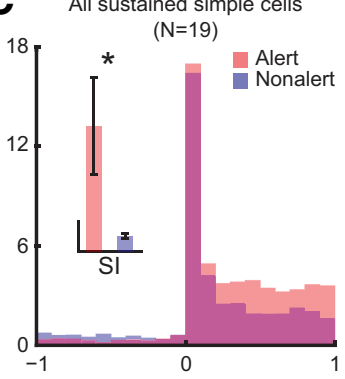

$\mathbf{F}$

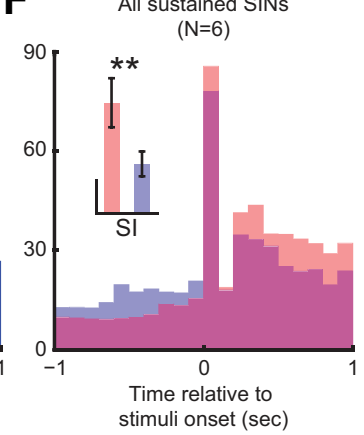

Figure 9. Both sustained simple cells and sustained SINs have higher sustained response during the alert than during the nonalert state. Each figure plots the cell's response PSTH to optimal flashing stationary stimulus during either state (red, alert; blue, nonalert). $\boldsymbol{A}, \boldsymbol{B}$, Responses from a sustained simple cell. $\boldsymbol{C}$, Population average responses of all sustained simple cells $(N=19)$. $\boldsymbol{D}$, $\boldsymbol{E}$, Responses from a sustained SIN. $\boldsymbol{F}$, Population average responses of all sustained SINs $(N=6)$. Inset, Comparison of SI between the alert and the nonalert state for each population. Vertical calibration for simple cells, 10; for SINs, 1. Note that the transient component of the response was little affected by state. ${ }^{* *} p<0.01$; ${ }^{*} p<0.05$; paired $t$ test.

cells' responses at high contrast and to stimuli moving in the direction orthogonal to the preferred direction. For SINs, the alert state also increased response strength and reliability while maintaining response linearity and other tuning properties. Finally, model simulation showed that three separable effects of alertness on layer 4 simple cells (increase of reliability, increase of response strength, increase of selective suppression) could each significantly enhance the speed of cortical feature detection during the alert state.

\section{Cell populations of this study}

The inhibitory interneurons in layer 4 are heterogeneous. In mouse V1 layer 4, parvalbumin-positive neurons $(\sim 50 \%)$ and somatostatin-positive neurons $(\sim 20 \%)$ account $>70 \%$ of total GABAergic cell population (Xu et al., 2010). However, we believe that the vast majority of our SINs are PV + fast spiking interneurons, because they have narrow spike waveforms and receive strong direct thalamocortical inputs (Swadlow, 2003; Cruikshank et al., 2007; Zhuang et al., 2013), whereas somatostatinpositive neurons have broader spike waveforms and only receive weak thalamocortical inputs (Cruikshank et al., 2010). However, because some somatostatin-positive neurons may have simple receptive field characteristics (Ma et al., 2010), we cannot exclude the possibility that some of these cells may be included in our simple cell group.

\section{Alert/nonalert state effects in LGN and V1}

Because LGN neurons are strongly affected by brain state and layer 4 is the major recipient of LGN inputs in visual cortex, it is important to understand how LGN and cortical layer 4 are differently affected by brain state. Some effects in LGN and cortical layer 4 were only quantitatively different. (1) Both LGN cells and layer 4 cells increased their visual responses to drifting gratings during the alert state but the effects were much stronger in LGN ( $~ 88 \%$ increase during alert state for LGN cells; Cano et al., 2006; 44\% for layer 4 simple cells, $\sim 33 \%$ for layer 4 SINs; Fig. $2 A, B$ ). (2) Both LGN cells and layer 4 cells increased their response reliability during the alert state, but the increased in response reliability was more pronounced in cortical cells (average Fano factor decreased by $\sim 17 \%$ during the alert state for LGN cells; Fig. 3C, inset; $~ 32 \%$ for layer 4 simple cells and $\sim 50 \%$ for layer 4 SINs; Fig. $3 C, D)$. Some effects were almost identical in LGN and cortical layer 4. During the alert state, sustained cells in both LGN (Swadlow and Weyand, 1985; Bezdudnaya et al., 2006) and layer 4 (Fig. 9) increased their sustained responses to stationary stimuli and broadened their temporal frequency tuning.

Some effects of brain state were specific for layer 4 simple cells. (1) The alert state increased the orientation selectivity of simple cells by selectively enhancing responses in the preferred orientation/direction and suppressing them in the orthogonal orientation/direction (Fig. 5). These effects are not found in LGN cells with concentric RFs. Interestingly, in directionally selective LGN neurons, alertness also suppresses responses to movement in the null direction (Hei et al., 2012). (2) The alert state suppressed the responses of a large number of simple cells to high-contrast stimuli (Fig. 6A,B). Such high-contrast suppression is much weaker and rare in LGN cells (Cano et al., 2006). Therefore, some of the effects of alertness at the input layers of the cortex are relayed from LGN, some are amplified, and others are novel to the cortex.

\section{Alert/nonalert state effects beyond multiplicative gain modulation}

Changes in response strength have been proposed to account for a variety of neurophysiological functions (Salinas and Sejnowski, 2001). It is previously shown that brain state changes in the contrast response function of LGN neurons are largely explained by a multiplicative gain change (Cano et al., 2006). Consistently, in the current study, layer 4 neurons change response gain between the alert and the nonalert state without changing contrast sensitivity $\left(\mathrm{C}_{50}\right)$, orientation tuning width $(\mathrm{HWHH})$, spatial frequency tuning peak, and width and temporal frequency tuning peak. However, several other effects of brain state on cortical layer 4 cannot be explained by a multiplicative gain model, such as the increase in suppression to stimulus directions orthogonal to the preferred direction, high-contrast suppression, and the pronounced increase in response reliability. The increase in response reliability during the alert state was profound, and was independent of the increase in mean firing rate. In fact, although all layer 4 cells increased their response reliability during the alert state (Fig. 4C), some SINs decreased their mean firing rates (Figs. $2 A$, inset, Fig. $4 C$ ). These results demonstrate that the alert state does more than amplify visual responses; it selectively increases 
A

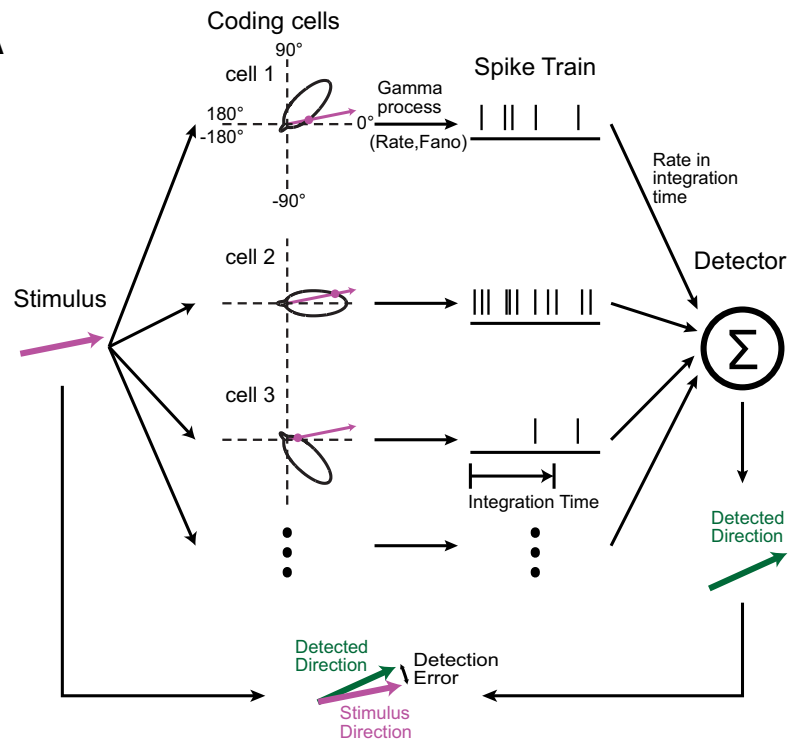

B

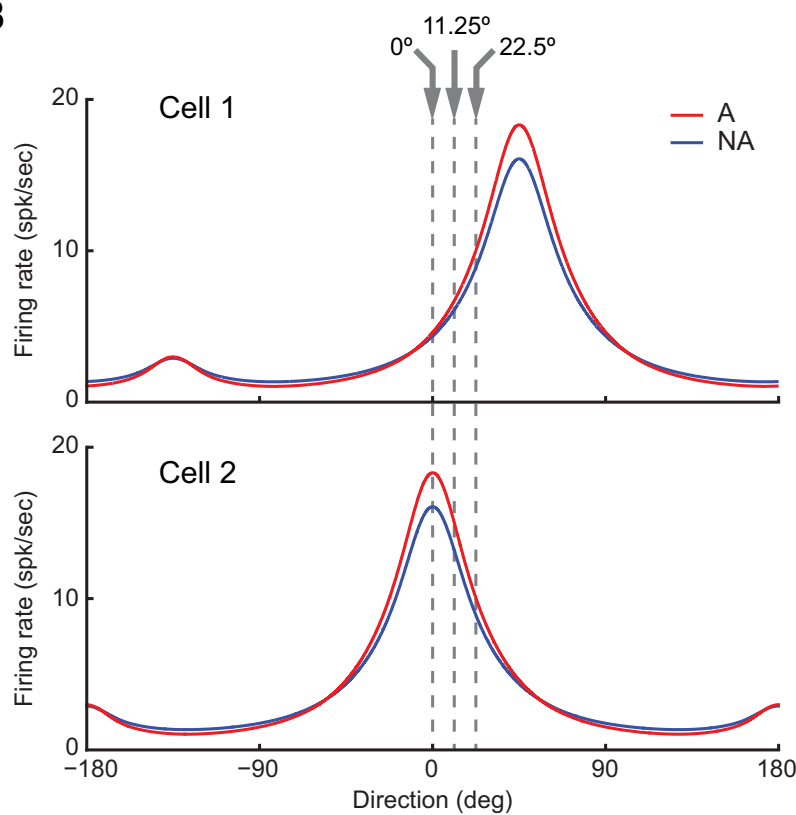

C

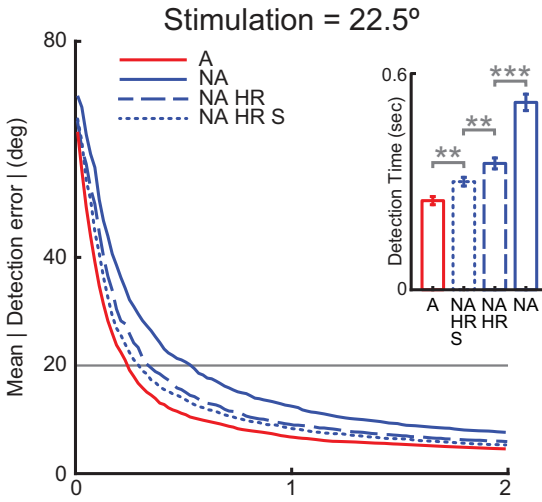

D

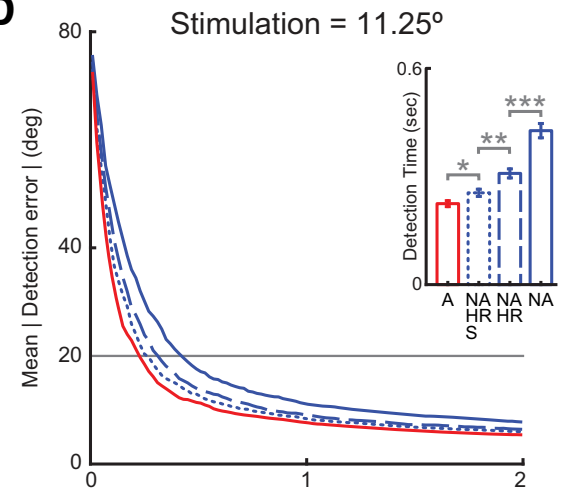

E

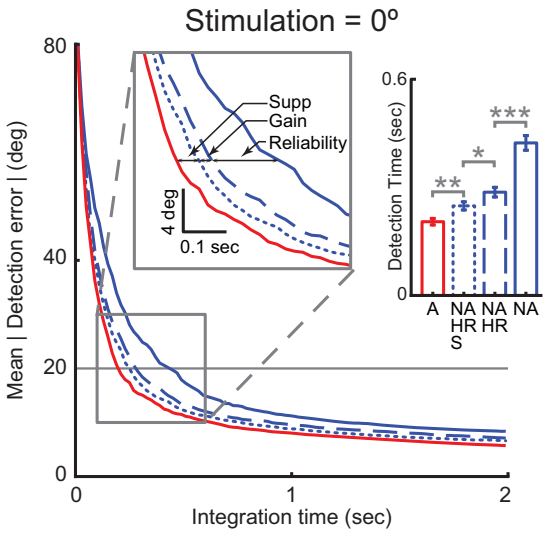

Figure 10. Model showing that high reliability, enhanced gain and orthogonal suppression all contribute to the increase of detection speed during the alert state. $\boldsymbol{A}$, Diagram of direction detection model. When stimulated in certain direction, each of eight simulated simple cells generates a spike train. Firing rates of simulated spike trains within integration time window were fed to a vector sum detector to detect stimulus direction. A detection error was measured to evaluate the performance of the system. $\boldsymbol{B}$, Direction tuning curves of two example cells in a. Each of the eight simulated cells have identical tuning curve shapes as the simple cell population average shown in Figure $5 B$, but with preferred directions every $45^{\circ}$ apart. Gray dashed lines indicate three simulated stimulus directions. $\boldsymbol{C}, \boldsymbol{D}, \boldsymbol{E}$, The relationship between integration time and detection error under each of three stimulating directions. Horizontal line indicates threshold ( $\left.20^{\circ}\right)$ for measuring detection time. $\boldsymbol{C}, \boldsymbol{E}$, Insets indicate statistical results. $\boldsymbol{E}$, Gray box was magnified to show the contributions of each component of state effects to the increase of computational speed in the alert state. Supp: Orthogonal suppression.

responses to preferred directions of motion and suppresses responses to nonpreferred directions and high contrasts. Our direction detection model (Fig. 10) demonstrates that the combined increase in response strength, reliability and selective suppression can have an important impact on the speed of cortical feature detection.

\section{Comparisons to previous studies in awake subjects}

It is important to emphasize that the EEG-defined alert/nonalert brain states studied here are "global" brain states, not local states, such as those generated by selective attention (Kastner and Ungerleider, 2000; Reynolds and Chelazzi, 2004; Maunsell and
Treue, 2006; Anton-Erxleben and Carrasco, 2013). Other studies on rodents have found some awake brain states were associated with cortical desynchronization (Poulet and Petersen, 2008; Niell and Stryker, 2010; Pinto et al., 2013), similar to our alert state. However, it is important to note that the brain states previously studied by others may not be directly comparable to the awake alert versus awake-but-nonalert brain states examined here. For example, Niell and Stryker (2010) compared the visual response properties of V1 simple cells and putative fast-spike interneurons when mice were running versus balancing on a ball, and found the "running" state increases responsiveness of layer $2 / 3$ regularspike cells, but has diverse effects on firing rates of narrow-spike 
cells. However, whereas these authors concluded that the LGN does not contribute significantly to the effects seen at the cortex (no changes in LGN response magnitude during locomotion), we have previously shown that LGN cells are powerfully influenced by state (Swadlow and Weyand, 1985; Bezdudnaya et al., 2006; Cano et al., 2006) suggesting that some of the effects seen in layer 4 are inherited from the LGN, whereas others are not. A recent intracellular study using the same state classification as Niell and Stryker (2010) found that both excitatory cells and parvalbuminpositive inhibitory interneurons in mouse V1 layer 4 show elevated membrane potential and less membrane potential fluctuation when the animal was running (Polack et al., 2013) and another study found enhanced reliability during stimulation of the nucleus basalis (Pinto et al., 2013). These results are consistent with the increased responsiveness and reliability for both layer 4 simple cells and layer 4 SINs during the alert state reported here.

\section{The significance of getting drowsy}

The mechanisms of visual attention in the awake, alert brain have been intensely studied (Kastner and Ungerleider, 2000; Reynolds and Chelazzi, 2004; Maunsell and Treue, 2006; Anton-Erxleben and Carrasco, 2013). However, awake subjects are not always alert and attentive. In familiar environments, they readily switch between alert and nonalert states, yet they must be able to perceive salient features in their environment when nonalert. Here, we show that a nonalert, "drowsy" state significantly reduces response gain, reliability, and suppression to nonpreferred stimuli in primary visual cortex. Moreover, our simulations demonstrate that each of these factors can reduce computation speed during the alert state. Thus drowsiness strongly affects visual information processing at very early stage, and this raises questions concerning changes in perception (Dorokhov et al., 1998; Rogé et al., 2002) and behavior that have been associated with drowsiness. For example, "drowsy driving" kills $>1000$ people and causes tens of thousands of injuries each year in the United States alone (National Highway Traffic Safety Administration, 2011), and it is sometimes assumed that this is largely due to the increased likelihood of falling asleep when nonalert. By contrast, the present results suggest that staterelated changes in perceptual mechanisms, including the computational speed underlying perceptual discriminations, may play an important role in such statistics.

\section{References}

Albrecht DG, Hamilton DB (1982) Striate cortex of monkey and cat: contrast response function. J Neurophysiol 48:217-237. Medline

Anton-Erxleben K, Carrasco M (2013) Attentional enhancement of spatial resolution: linking behavioural and neurophysiological evidence. Nat Rev Neurosci 14:188-200. CrossRef Medline

Bereshpolova Y, Stoelzel CR, Zhuang J, Amitai Y, Alonso JM, Swadlow HA (2011) Getting drowsy? Alert/nonalert transitions and visual thalamocortical network dynamics. J Neurosci 31:17480-17487. CrossRef Medline

Bezdudnaya T, Cano M, Bereshpolova Y, Stoelzel CR, Alonso JM, Swadlow HA (2006) Thalamic burst mode and inattention in the awake LGNd. Neuron 49:421-432. CrossRef Medline

Cano M, Bezdudnaya T, Swadlow HA, Alonso JM (2006) Brain state and contrast sensitivity in the awake visual thalamus. Nat Neurosci 9:12401242. CrossRef Medline

Castro-Alamancos MA (2004) Absence of rapid sensory adaptation in neocortex during information processing states. Neuron 41:455-464. CrossRef Medline

Chen Y, Anand S, Martinez-Conde S, Macknik SL, Bereshpolova Y, Swadlow HA, Alonso JM (2009) The linearity and selectivity of neuronal responses in awake visual cortex. J Vis 9(9):12 11-17. CrossRef Medline

Cruikshank SJ, Lewis TJ, Connors BW (2007) Synaptic basis for intense thalamocortical activity of feedforward inhibitory cells in neocortex. Nat Neurosci 10:462-468. CrossRef Medline

Cruikshank SJ, Urabe H, Nurmikko AV, Connors BW (2010) Pathwayspecific feedforward circuits between thalamus and neocortex revealed by selective optical stimulation of axons. Neuron 65:230-245. CrossRef Medline

Dorokhov VB, Dementienko VV, Koreneva LG, Markov AG, Shakhnarovitch VM (1998) 240 Estimation of the time delay between performance error and its subjective perception during drowsiness. Int J Psychophysiol 30: 95. CrossRef

Fanselow EE, Nicolelis MA (1999) Behavioral modulation of tactile responses in the rat somatosensory system. J Neurosci 19:7603-7616. Medline

Gentet LJ, Avermann M, Matyas F, Staiger JF, Petersen CC (2010) Membrane potential dynamics of GABAergic neurons in the barrel cortex of behaving mice. Neuron 65:422-435. CrossRef Medline

Goard M, Dan Y (2009) Basal forebrain activation enhances cortical coding of natural scenes. Nat Neurosci 12:1444-1449. CrossRef Medline

Harris KD, Thiele A (2011) Cortical state and attention. Nat Rev Neurosci 12:509-523. CrossRef Medline

Hei X, Stoelzel CR, Zhuang J, Bereshpolova Y, Huff J, Alonso JM, Swadlow HA (2012) Brain state and direction-selective cells in the dorsal lateral geniculate nucleus of awake rabbit. Soc Neurosci Abstr 880:18.

Jin J, Wang Y, Lashgari R, Swadlow HA, Alonso JM (2011) Faster thalamocortical processing for dark than light visual targets. J Neurosci 31:1747117479. CrossRef Medline

Kastner S, Ungerleider LG (2000) Mechanisms of visual attention in the human cortex. Annu Rev Neurosci 23:315-341. CrossRef Medline

Lee SH, Dan Y (2012) Neuromodulation of brain states. Neuron 76:209_ 222. CrossRef Medline

Ma WP, Liu BH, Li YT, Huang ZJ, Zhang LI, Tao HW (2010) Visual representations by cortical somatostatin inhibitory neurons-selective but with weak and delayed responses. J Neurosci 30:14371-14379. CrossRef Medline

Maunsell JH, Treue S (2006) Feature-based attention in visual cortex. Trends Neurosci 29:317-322. CrossRef Medline

Nawrot MP, Boucsein C, Rodriguez Molina V, Riehle A, Aertsen A, Rotter S (2008) Measurement of variability dynamics in cortical spike trains. J Neurosci Methods 169:374-390. CrossRef Medline

Niell CM, Stryker MP (2010) Modulation of visual responses by behavioral state in mouse visual cortex. Neuron 65:472-479. CrossRef Medline

Nowak LG, Sanchez-Vives MV, McCormick DA (2008) Lack of orientation and direction selectivity in a subgroup of fast-spiking inhibitory interneurons: cellular and synaptic mechanisms and comparison with other electrophysiological cell types. Cereb Cortex 18:1058-1078. CrossRef Medline

Otazu GH, Tai LH, Yang Y, Zador AM (2009) Engaging in an auditory task suppresses responses in auditory cortex. Nat Neurosci 12:646-654. CrossRef Medline

Peirce JW (2007) The potential importance of saturating and supersaturating contrast response functions in visual cortex. J Vis 7(6):13 1-10. CrossRef Medline

Pinto L, Goard MJ, Estandian D, Xu M, Kwan AC, Lee SH, Harrison TC, Feng G, Dan Y (2013) Fast modulation of visual perception by basal forebrain cholinergic neurons. Nat Neurosci 16:1857-1863. CrossRef Medline

Polack PO, Friedman J, Golshani P (2013) Cellular mechanisms of brain state-dependent gain modulation in visual cortex. Nat Neurosci 16:13311339. CrossRef Medline

Poulet JF, Petersen CC (2008) Internal brain state regulates membrane potential synchrony in barrel cortex of behaving mice. Nature 454:881-885. CrossRef Medline

Reynolds JH, Chelazzi L (2004) Attentional modulation of visual processing. Annu Rev Neurosci 27:611-647. CrossRef Medline

Rogé J, Kielbasa L, Muzet A (2002) Deformation of the useful visual field with state of vigilance, task priority, and central task complexity. Percept Mot Skills 95:118-130. CrossRef Medline

Salinas E, Sejnowski TJ (2001) Gain modulation in the central nervous system: where behavior, neurophysiology, and computation meet. Neuroscientist 7:430-440. CrossRef Medline

Stoelzel CR, Bereshpolova Y, Gusev AG, Swadlow HA (2008) The impact of an LGNd impulse on the awake visual cortex: synaptic dynamics and the 
sustained/transient distinction. J Neurosci 28:5018-5028. CrossRef Medline

Stoelzel CR, Bereshpolova Y, Swadlow HA (2009) Stability of thalamocortical synaptic transmission across awake brain states. J Neurosci 29:68516859. CrossRef Medline

Swadlow HA (1988) Efferent neurons and suspected interneurons in binocular visual cortex of the awake rabbit: receptive fields and binocular properties. J Neurophysiol 59:1162-1187. Medline

Swadlow HA (1989) Efferent neurons and suspected interneurons in S-1 vibrissa cortex of the awake rabbit: receptive fields and axonal properties. J Neurophysiol 62:288-308. Medline

Swadlow HA (1991) Efferent neurons and suspected interneurons in second somatosensory cortex of the awake rabbit: receptive fields and axonal properties. J Neurophysiol 66:1392-1409. Medline

Swadlow HA (1994) Efferent neurons and suspected interneurons in motor cortex of the awake rabbit: axonal properties, sensory receptive fields, and subthreshold synaptic inputs. J Neurophysiol 71:437-453. Medline

Swadlow HA (1995) Influence of VPM afferents on putative inhibitory interneurons in S1 of the awake rabbit: evidence from cross-correlation, microstimulation, and latencies to peripheral sensory stimulation. J Neurophysiol 73:1584-1599. Medline

Swadlow HA (2003) Fast-spike interneurons and feedforward inhibition in awake sensory neocortex. Cereb Cortex 13:25-32. CrossRef Medline
Swadlow HA, Gusev AG (2001) The impact of "bursting" thalamic impulses at a neocortical synapse. Nat Neurosci 4:402-408. CrossRef Medline

Swadlow HA, Weyand TG (1985) Receptive-field and axonal properties of neurons in the dorsal lateral geniculate nucleus of awake unparalyzed rabbits. J Neurophysiol 54:168-183. Medline

Swadlow HA, Weyand TG (1987) Corticogeniculate neurons, corticotectal neurons, and suspected interneurons in visual cortex of awake rabbits: receptive-field properties, axonal properties, and effects of EEG arousal. J Neurophysiol 57:977-1001. Medline

Swadlow HA, Bereshpolova Y, Bezdudnaya T, Cano M, Stoelzel CR (2005) A multi-channel, implantable microdrive system for use with sharp, ultra-fine "Reitboeck" microelectrodes. J Neurophysiol 93:2959-2965. CrossRef Medline

Wörgötter F, Suder K, Zhao Y, Kerscher N, Eysel UT, Funke K (1998) Statedependent receptive-field restructuring in the visual cortex. Nature 396: 165-168. CrossRef Medline

Xu X, Roby KD, Callaway EM (2010) Immunochemical characterization of inhibitory mouse cortical neurons: three chemically distinct classes of inhibitory cells. J Comp Neurol 518:389-404. CrossRef Medline

Zhuang J, Stoelzel CR, Bereshpolova Y, Huff JM, Hei X, Alonso JM, Swadlow HA (2013) Layer 4 in primary visual cortex of the awake rabbit: contrasting properties of simple cells and putative feedforward inhibitory interneurons. J Neurosci 33:11372-11389. CrossRef Medline 